PREDICTING IMPACT OF BIOCHAR ON SATURATED HYDRAULIC CONDUCTIVITY OF NATURAL AND ENGINEERED MEDIA

by

Yudi Yan

A thesis submitted to the Faculty of the University of Delaware in partial fulfillment of the requirements for the degree of Master of Civil Engineering

Fall 2017

(C) 2017 Yudi Yan

All Rights Reserved 


\section{PREDICTING IMPACT OF BIOCHAR ON SATURATED HYDRAULIC CONDUCTIVITY OF NATURAL AND ENGINEERED MEDIA}

by

Yudi Yan

Approved:

Paul T. Imhoff, Ph.D.

Professor in charge of thesis on behalf of the Advisory Committee

Approved:

Sue McNeil, Ph.D.

Chair of the Department of Civil and Environmental Engineering

Approved:

Babatunde A. Ogunnaike, Ph.D.

Dean of the College of Engineering

Approved:

Ann L. Ardis, Ph.D.

Senior Vice Provost for Graduate and Professional Education 


\section{ACKNOWLEDGMENTS}

I would like to give my gratitude to my professor at the University of Delaware, Dr. Paul Imhoff, my friend Seyyedaliakbar Nakhli (Ali)s, Tian Jing and Jin Jing for their advice in the past two years. It is an honor for me to have the great opportunity to work with them and learn from them.

Finally, I would also like to thank the Delaware Department of Transportation

and National Fish and Wildlife Foundation for providing funding over the duration of my studies. 


\section{TABLE OF CONTENTS}

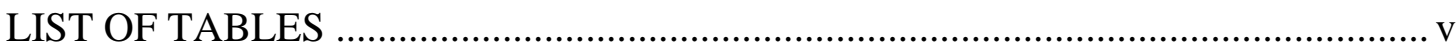

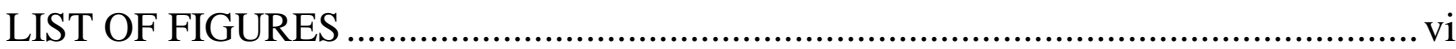

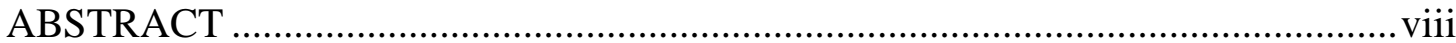

Chapter

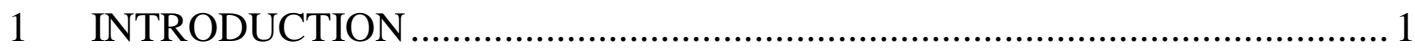

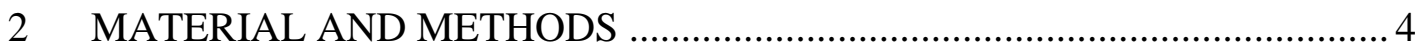

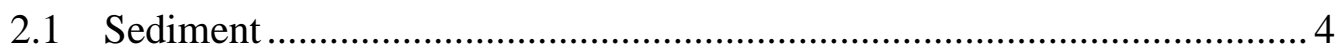

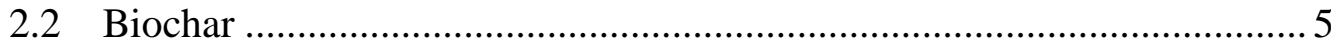

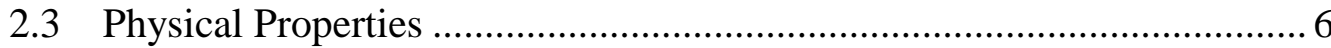

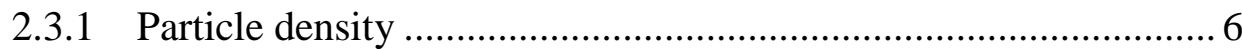

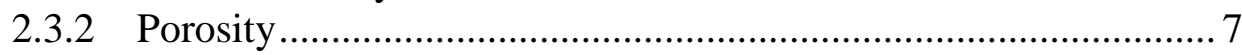

2.4 Hydraulic Properties ............................................................................. 8

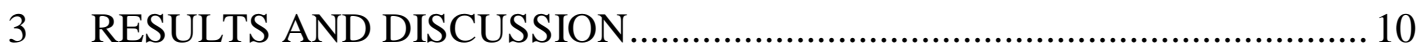

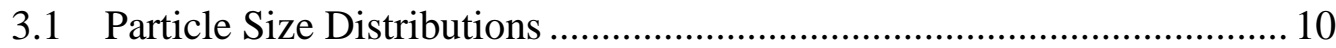

3.2 Saturated Hydraulic Conductivity …………………........................... 14

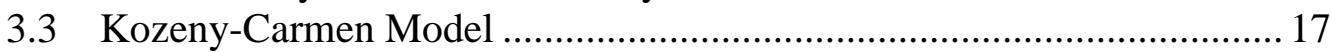

3.3.1 Envelope Density and Interporosity ……………...................... 18

3.3.2 Estimation of Specific Surface Area …………........................... 19

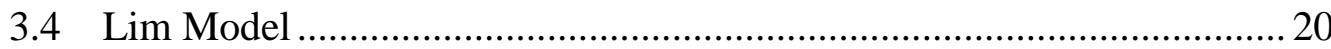

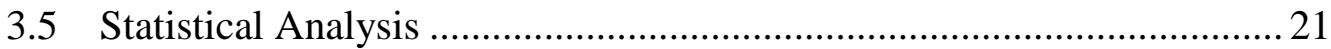

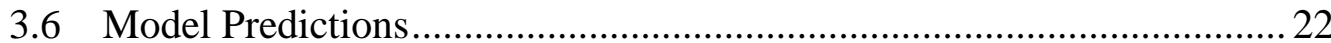

3.6.1 Relation between K and Sediment Texture ..................................30

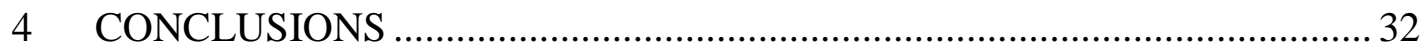

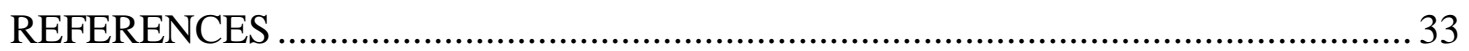

Appendix

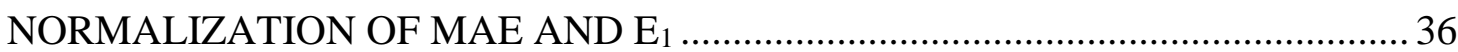




\section{LIST OF TABLES}

Table 3.1: Properties of uniform sands, natural soil, and bioretention media with different size fractions of biochar........................................................... 13

Table 3.2: $\quad$ Physical properties of column packings and measured and K-C model predicted saturated hydraulic conductivities ............................................ 15

Table 3.3: $\quad \Delta \mathrm{K}_{\mathrm{m}}$ and $\Delta \mathrm{K}_{\mathrm{p}}$ using $\mathrm{K}-\mathrm{C}$ and Lim models............................................2 26

Table 3.4: The MAE and $\mathrm{E}_{1}$ for $\mathrm{K}-\mathrm{C}$ and Lim model predictions of $\log (\mathrm{K})$. The shaded numbers represent the best prediction for each row.................... 28

Table 3.5: $\quad$ MAE and $\mathrm{E}_{1}$ for $\mathrm{K}-\mathrm{C}$ and Lim model predictions of $\log (\mathrm{K})$ excluding large biochar particle samples (ACS (35)-6L, ACS (35)-6L*, ACS (40)-4L and BIM-4L). The shaded numbers represent the best prediction for each row

Table 3.6: The MAE and $\mathrm{E}_{1}$ of $\Delta \mathrm{Km}$ and $\Delta \mathrm{Kp}$ from equations (3-11) and (3-12), respectively, for $\mathrm{K}-\mathrm{C}$ and Lim models. The shaded numbers represent the best prediction for each row.

Table 3.7: The MAE and $\mathrm{E}_{1}$ of $\Delta \mathrm{Km}$ and $\Delta \mathrm{Kp}$ from equations (3-11) and (3-12), respectively, for K-C and Lim models excluding large particle biochar samples (ACS (35)-6L, ACS (35)-6L*, ACS (40)-4L and BIM-4L). The shaded numbers represent the best prediction for each row.

Table 3.8: Relation between $\mathrm{d}_{50}$ and $\mathrm{K}$

Table A.1: The MAE and $\mathrm{E}_{1}$ of $\log (\mathrm{K})$ for different sediments and different models (K-C model and Lim's model). The shaded numbers represent the best prediction for each row.

Table A.2: The MAE and $\mathrm{E}_{1}$ of delta $\mathrm{K}(\Delta \mathrm{Km}$ and $\Delta \mathrm{Kp}$ in Equation (3-10) and (3$11)$, respectively) for different sediments and different models (K-C model and Lim model). The shaded numbers represent the best prediction for each row.

Table A.3: The Max. Reynolds for all the sediments. 


\section{LIST OF FIGURES}

Figure 3.1: A Particle size distribution both by mass and volume for ACS (35)$6 \mathrm{U}$, and BIM-4U. B Particle size distribution both by mass and volume for SIL-6U. Abbreviations are defined in Table 3.1.

Figure 3.2: A Particle size distribution by mass for ACS (35), ACS (40), SIL, SAL, LOS, and BIM. B Particle size distribution by mass for different biochar samples. Abbreviations are defined in Table 3.1.

Figure 3.3: The relationship between interporosity and measured $\mathrm{K}(\mathrm{A})$, and interporosity and $\mathrm{K}-\mathrm{C}$ model predicted $\mathrm{K}$ (equation 3-3) (B). Linear regressions were conducted weighting the data by the inverse of the squared standard error of measured K. Error bars in the plots are too small to be visible.

Figure 3.4: A. and B. Predicted versus measured K computed using equation (3-3) for uniform sands, natural soils and bioretention media. Error bars are \pm one standard error and most area so small as not to be visible. Dashed lines represent $3 \mathrm{X}$ differences between model-predicted and measured K.

Figure 3.5: Predicted $\mathrm{K}$ from the Lim model versus measured K. Error bars are \pm one standard error and most are so small as not to be visible. Dashed lines represent $3 \mathrm{X}$ differences between model-predicted and measured K.

Figure 3.6: $\Delta \mathrm{Km}$ vs $\Delta \mathrm{Kpfor}$ Accusand and BIM (A) or for natural soils (B) using $\mathrm{K}-\mathrm{C}$ and Lim models. Data in the top right and bottom left quadrants of each plot are where sign of $\Delta \mathrm{Km}$ and $\Delta \mathrm{Kp}$ are identical.

Figure A.1: A contains ACS (30/35) and Small biochar (0.001-0.059 mm). B contains ACS (30/35) and medium biochar $(0.5-0.59 \mathrm{~mm})$. C contains ACS (30/35) and large biochar (2-4.75 mm). D contains ACS (30/35) and unsieved biochar $(<4.75 \mathrm{~mm})$.

Figure A.2: The image of soil from right to left is silt loam, sandy loam and loam sand.

Figure A.3: Bioretention media. 
Figure A.4: A: small biochars $(<0.841 \mathrm{~mm})$, B: unsieved biochars $(<2 \mathrm{~mm}), \mathrm{C}$ : large biochars $(0.841-4.75 \mathrm{~mm}), \mathrm{D}$ : small biochars $(0.001-0.059 \mathrm{~mm})$, E: medium biochars $(0.5-0.59 \mathrm{~mm}), \mathrm{F}$ : large biochars $(2-4.75 \mathrm{~mm}), \mathrm{G}$ : and unsieved biochars $(<4.75 \mathrm{~mm})$.

Figure A.5: A. and B. Predicted versus measured K values computed by K-C model with $S_{\mathrm{m}}$ and interporosity for the uniform sands, natural soils and bioretention media. The error bars in the plots are too small to be visible. 


\begin{abstract}
Biochar application to agricultural soil may improve soil physical and chemical properties and promote sustainable management of natural resources. Biochar has also been proposed as an amendment to stormwater treatment media, including both bioretention media and roadway soils. In both applications, the effect of biochar on the saturated hydraulic conductivity $(K)$ of the amended media is a critical factor affecting soil or stormwater treatment performance. The objective of this research was to advance models for predicting $K$ of natural soil and bioretention media amended with biochar of different particle size and mass. Experiments were conducted using three natural soils, silt loam, loamy sand, and sandy loam, amended with unsieved biochar ( $2 \%$ and $6 \%$ by w/w); a uniform sand amended with six different sizes of biochar $(4 \%$ and $6 \% \mathrm{w} / \mathrm{w})$; and a bioretention medium amended with three different sizes of biochar $(4 \% \mathrm{w} / \mathrm{w})$. Experimental measurements of $K$ in these media showed a strong positive correlation between the interporosity of each sediment/biochar medium and $K$. The classical Kozeny-Carman equation was able to describe the data better than a more recently proposed model for biochar-amended soil, the Lim model, as long as the total porosity in the Kozeny-Carman model is replaced by the interporosity. If the objective is instead to predict the relative change in $K$ with biochar-amendment, the Lim model performed better overall. These results can be used to guide selection of biochar to improve the hydraulic properties of natural soils and bioretention media.
\end{abstract}




\section{Chapter 1}

\section{INTRODUCTION}

Biochar is a charcoal product produced in high-heat $\left(300^{\circ} \mathrm{C}-850^{\circ} \mathrm{C}\right)$ and lowoxygen conditions that can be used as a soil amendment with the potential for enhancing soil properties and plant growth (Brantley et al. 2015). Biochar is made from diverse biomass (feedstock) and pyrolysis conditions (Mukherjee and Lal 2013), which results in a wide variety of biochar morphological and chemical properties. Biochar has a relative high porosity and large specific surface area, and amending soil with biochar can alter soil physical properties, such as particle size distribution, and bulk density. In addition, biochar amendment may affect soil hydraulic properties, for example, soil water retention capacity and hydraulic conductivity (Lei and Zhang 2013).

Amending soils with biochar can increase crop productivity, potentially by improving the hydrologic properties of soil (Barnes, Gallagher et al. 2014). Biochar amendment is also potentially important for addressing two globally important issues climate change and sustainable soil management (Chan, Van Zwieten et al. 2007) . Sandy soils amended with biochar will drain more slowly, and clay-rich soils amended with biochar will drain more quickly (Barnes, Gallagher et al. 2014), both beneficial changes. The impact of biochar on soil hydraulic properties is a complex interaction of soil and biochar physical properties.

Several studies have reported that incorporation of biochar to soil increased, decreased, or had no significant effect on the saturated hydraulic conductivity $(K)$ 
(Asai, Samson et al. 2009, Githinji 2013, Lim, Spokas et al. 2016). Lei and Zhang reported soils amended with biochar (dairy manure and woodchip biochars pyrolyzed at temperatures of 300,500 , and $700^{\circ} \mathrm{C}$ ) had increased $K$, and the effect increased with increasing pyrolysis temperature of biochar (Lei and Zhang 2013). Githinji (2013) produced biochar from peanut hulls using slow pyrolysis at $500^{\circ} \mathrm{C}$ for $1 \mathrm{~h}$ and found that $K$ decreased from 0.49 to $0.18 \mathrm{~cm} / \mathrm{min}$ as biochar content increased from 0 to $100 \%$ (v/v) (Githinji 2013). However, in another field study application of a commercial wood biochar at $16 \mathrm{tha}^{-1}$ increased $K$ by $79 \%$ in the top $0-5 \mathrm{~cm}$ after 60 days of incubation (Asai, Samson et al. 2009).

For various feedstock materials and/or pyrolysis conditions, $K$ has been found to change over time (Devereux, Sturrock et al. 2013, Lei and Zhang 2013). For example, $K$ initially decreased from $4.8 \times 10^{-3}$ to $2.3 \times 10^{-3} \mathrm{~cm} / \mathrm{s}$ with increasing biochar content at the early time of experiment (Devereux, Sturrock et al. 2013). At the end of experiment after wheat root growth occurred, $K$ was found to increase with biochar content (Devereux, Sturrock et al. 2013). Thus, there are dynamic changes in soil structure associated with biochar addition that may not be captured in experiments that neglect plant growth and associated time-dependent changes in soil microbiology. While there are many observational studies documenting biochar's impact on $K$, very few studies discuss the mechanisms by which biochar alters $K$, e.g., changes in soil interparticle porosity.

The objectives of this study are to (1) measure $K$ in a controlled laboratory setting when wood biochar at two mass fractions is added into three natural soils - silt loam, loamy sand, and sandy loam; (2) measure $K$ when different sizes of this same 
biochar is added to bioretention media or a uniform sand; and (3) evaluate two models for describing saturated hydraulic conductivity of biochar-amended media. 
Chapter 2

\section{MATERIAL AND METHODS}

\subsection{Sediment}

Six types of sediment were employed in this study: Accusand 30/35, Accusand 30/40, silt loam, loamy sand, sandy loam, and a well-defined bioretention media. Accusand 30/35 (ACS (30/35)) and Accusand 30/40 (ACS (30/40)) are silica sand (Unimin, Pittsburgh, PA) that was pre-sieved between \#30 (0.59 mm) and \#35 (0.5 $\mathrm{mm})$, and between \#30 (0.59 $\mathrm{mm})$ and \#40 (0.425 mm) sieves, respectively. Silt loam (SIL), sandy loam, and loamy sand (LOS) were collected from University of Delaware farm land $\left(39^{\circ} 40^{\prime} 11.1^{\prime \prime} \mathrm{N} 75^{\circ} 45^{\prime} 08.7^{\prime \prime} \mathrm{W}\right)$, a highway roadway $\left(39^{\circ} 31^{\prime} 52.1^{\prime \prime} \mathrm{N}\right.$ $\left.75^{\circ} 44^{\prime} 12.6^{\prime \prime} \mathrm{W}\right)$, and University of Delaware farm land (3940'21.4"N 7544'30.0"W), respectively. To make the loamy sand somewhat coarser, loamy sand was sieved to selectively remove some particles smaller than \#200 sieve. These three soils are referred to as natural soils below.

Bioretention media (BIM) is a sediment mixture that includes $88 \% \mathrm{C} 33$ concrete sand $\left(d_{50}=0.595 \mathrm{~mm}\right.$, Mason- Dixon Sand \& Gravel, Port Deposit, MD), $8 \%$ clay (Mason-Dixon Sand \& Gravel, Port Deposit, MD), and 4\% sawdust (roughly between 0.2 to $1 \mathrm{~mm}$ by visual observation, Second Chance Hardwoods, Elkton, MD) by mass, or $62 \%$ C33 sand, $11 \%$ clay, and $27 \%$ sawdust by volume. The ACS (30/35), ACS (30/40), and BIM were oven-dried at $105^{\circ} \mathrm{C}$ for $24 \mathrm{~h}$ and stored in a sealed

container before use. Natural soils were all ground using a mortar and pestle to remove large soil aggregates, oven-dried at $105^{\circ} \mathrm{C}$ for $24 \mathrm{~h}$ and stored in a sealed container before use. 


\subsection{Biochar}

Soil reef biochar (The Biochar Co., Berwyn, PA) produced through pyrolysis of Southern Yellow hardwood chips at $550^{\circ} \mathrm{C}$ was used in this study (referred as 'biochar' for simplicity). The biochar batch was purchased in Summer 2014 and was stored in open buckets at room temperature and humidity. All measurements and tests were performed beginning in February 2015.

All biochars were from the same batch of soil reef biochar, but some were sieved to different size fractions to evaluate the impact of biochar size (and thus shape) on $K$. The biochar was first rinsed and then sieved. Rinsing was used to remove possible organic coatings and readily solubilized salts. When rinsing, biochar was added to deionized (Steiakakis, Gamvroudis et al. 2012) water at 1:50 (biochar/DI water) mass ratio. Samples were gently rinsed until the electrical conductivity of the water decreased below $100 \mu \mathrm{S} / \mathrm{cm}$. Rinsed biochar when then oven dried at $105^{\circ} \mathrm{C}$ for $24 \mathrm{~h}$.

Rinsed biochar was sieved by mechanical sieving into seven particle classes: small, S (0.001-0.059 mm); small', S' (<0.85 mm); medium, M (0.5-0.59 mm); large, L (2-4.75 mm); large', L' (0.85-4.75 mm); unsieved, U (<4.75 mm), and unsieved', U' ( $<2 \mathrm{~mm})$. For each biochar class, a $200 \mathrm{~g}$ subsample was selected to determine the particle size distribution (PSD) using both mechanical sieves (ASTM 2014) and hydrometer tests, which were performed according to ASTM D422-63, using 152-H hydrometer (ASTM 2007). According to the standard procedure (ASTM 2014), at least $200 \mathrm{~g}$ of sample was placed on the mechanical shaker followed by a 15 minutes agitation, with sieves No. 4, 6, 8, 10, 14, 20, 30, 35, 40, 50, 60, 70, 100, 140, and 200. The hydrometer test involved dispersing samples that passed sieve No. 200 and taking hydrometer readings at $1,2,3,5,10,15,30,60,250$, and 1440 minutes (ASTM 2014). 


\subsection{Physical Properties}

\subsubsection{Particle density}

Skeletal density $\left(\rho_{s}\right)$ is the sample mass divided by the sample skeletal volume, where skeletal volume is the volume occupied only by the solid sample (Brewer et al., 2014). The skeletal density of Accusand, silt loam, loamy sand, sandy loam, and bioretention media were measured using a pycnometer (ASTM D854-06e1, 2006) and found to be $2.665 \mathrm{~g} / \mathrm{cm}^{3}, 2.658 \mathrm{~g} / \mathrm{cm}^{3}, 2.591 \mathrm{~g} / \mathrm{cm}^{3}, 2.667 \mathrm{~g} / \mathrm{cm}^{3}$, and $1.924 \mathrm{~g} / \mathrm{cm}^{3}$, respectively. The skeletal density of biochar was measured using mercury invasion porosimetry (ASTM 2010) and found to be $1.051 \pm 0.120 \mathrm{~g} / \mathrm{cm}^{3}$, where the \pm value here and below is one standard error. The skeletal density of mixtures of biochar and sediment packed into the experimental columns $\left(\rho_{s_{m i x}}\right)$ was calculated from

$$
\rho_{s_{\text {mix }}}=\frac{100 \%}{\frac{f_{\text {sed }}}{\rho_{S_{\text {sed }}}+\frac{f_{B C}}{\rho_{S_{B C} C}}}}
$$

$f_{\text {sed }}$ is the mass fraction of sediments without biochar in the mixture, and $f_{B C}$ is the

mass fraction of biochar in the mixture. The sum of $f_{\text {sed }}$ and $f_{B C}$ is equal to $100 \%$. $\rho_{s_{s e d}}$ is the skeletal densities of sediment.

Envelope density $\left(\rho_{e}\right)$ is the ratio of the mass of a particle to the sum of the volumes including the solid in each piece and the voids within close-fitting imaginary envelopes surrounding each piece (ASTM 2013) . Envelope density of biochar was measured using mercury intrusion porosimetry (ASTM 2010): $0.520 \pm 0.027 \mathrm{~g} / \mathrm{cm}^{3}$.

The envelope density of mixtures of biochar and sediment packed into the experimental columns $\left(\rho_{e_{m i x}}\right)$ was calculated from

$$
\rho_{e_{\text {mix }}}=\frac{100 \%}{\frac{f_{\text {sed }}}{\rho_{e_{s e d}}}+\frac{f_{B C}}{\rho_{e_{B C} C}}}
$$


$\rho_{e_{s e d}}$ is the envelope density of sediment without biochar, which for natural soil and Accusand was assumed equal to the skeletal densities of these materials.

\subsubsection{Porosity}

The pores in the packed columns of sediment and biochar consist of interpores, pores between particles, and intrapores, the internal voids of biochar. Intrapores of sediment particles are assumed negligible. There are two types of intrapores: (a) connected pores, which are connected to interpores; and (b) unconnected pores, which are isolated within the biochar particles (Liu, Dugan et al. 2016).

Total porosity $\left(\phi_{T}\right)$ is the ratio of total pore volume to total sample volume $\left(V_{T}\right)$, which includes pore volume and solid volume. Interporosity $\left(\phi_{\text {inter }}\right)$ is the ratio of interpore $\left(V_{\text {inter }}\right)$ volume to total volume of sediment sample. Intraporosity $\left(\phi_{\text {intra }}\right)$ is the ratio of intrapore volume $\left(V_{\text {intra }}\right)$ to total volume. Because intrapores are typically much smaller than interpores, we postulate that most water flows through interpores in a sediment samples containing biochar. As result, the interporosity is a better parameter for describing the behavior of $K$ than total porosity. The total porosity, interporosity, and intraporosity for a sediment sample amended or not amended with biochar are defined with respect to sample bulk density, envelop density and sample skeletal density as

$$
\begin{aligned}
& \phi_{T}=\frac{V_{\text {intra }}+V_{\text {inter }}}{V_{T}}=1-\frac{\rho_{b}}{\rho_{s}} \\
& \phi_{\text {inter }}=\frac{V_{\text {inter }}}{V_{T}}=1-\frac{\rho_{e}}{\rho_{s}}
\end{aligned}
$$




$$
\phi_{\text {intra }}=\frac{V_{\text {intra }}}{V_{T}}=\frac{\rho_{e}-\rho_{b}}{\rho_{s}}
$$

where dry bulk density $\left(\rho_{b}\right)$ of each packing was determined by dividing the sediment mass packed into each experimental column by the column volume. The total porosity, inter porosity and intraporosity for mixture are calculated by skeletal density, dry bulk density, and envelope density.

\subsection{Hydraulic Properties}

The seven different biochars were each combined at $2 \%, 4 \%$ or $6 \%(\mathrm{w} / \mathrm{w})$ (oven dry mass fraction) into six different sediments: ACS (30/35), ACS (30/40), silt loam, loamy sand, sandy loam, or BIM. Biochar/sediment samples were first thoroughly mixed in a bowl to provide a homogeneous sample. The sediment or sediment amended with biochar were then gently repacked into glass columns $5 \mathrm{~cm}$ inner diameter $\times 30 \mathrm{~cm}$ long with light tamping and vibration to reach targeted dry bulk densities. Two independent replicates of each sediment or sediment/biochar combination were prepared. All columns were fixed securely on laboratory stands. Columns were packed to achieve identical dry bulk densities as in complementary experiments conducted by Seyyedaliakbar Nakhli for water retention and unsaturated hydraulic conductivity measurements.

Dry packed columns were flushed upward with carbon dioxide gas for at least $1 \mathrm{~h}$ at a flow rate of approximately $30 \mathrm{~mL} / \mathrm{min}$ to displace air and saturate the column with a readily solubilized gas. The columns were then saturated with a solution of calcium sulfate and deionized water $(0.005 \mathrm{~mol} / \mathrm{L})$. The saturation step typically took two to three days to complete for each packing.

The constant head method (Jury 2004) was used to measure the $K$ of Accusand and biochar-amended Accusand samples (ACS (30/35), ACS (30/35)-6U, ACS 
(30/35)-6L, ACS (35)-6L*, ACS (30/35)-6M, ACS (30/40), ACS (30/40)-4S', ACS

(30/40)-4U', ACS (30/40)-4L', BIM, BIM-4S', BIM-4L', and BIM-4U'). To calculate $K$, the following equation was solved for each packed column

$$
Q=K \frac{\Delta H}{\Delta L}
$$

where $Q(\mathrm{~cm} / \mathrm{h})$ is volumetric flow rate, $\Delta L(\mathrm{~cm})$ is the length of soil sample, and $\Delta H$ $(\mathrm{cm})$ is the head difference between top and bottom of column that ranged between 3.9 $\mathrm{cm}$ and $9.7 \mathrm{~cm}$ for all experiments. Five different $\Delta H / \Delta L$ were used in each experiment, and data were linearly regressed to determine $K$ from equation (2-6). Experiments were conducted such that the experimental Reynolds number was maintained $<1.0$.

The falling head method (Jury 2004) was also used to measured $K$ of natural soil and soil with biochar (SIL, SIL-2U, SIL-6U, SAL, SAL-2U, SAL-6U, LOS, LOS$2 \mathrm{U}$, and LOS-6U). Linear regression was used to fit average $K$ for each sample column

$$
\ln \left(\frac{h_{i}}{h_{i+1}}\right)=K_{\text {sat }} \frac{\left(t_{i+1}-t_{i}\right)}{L}
$$

where $L$ is the length of the soil sample, $t_{i}$ is the $i^{\text {th }}$ time (s), $t_{i+l}$ is the time after $i^{\text {th }}$ time (s), $h_{i}$ is the $i^{\text {th }}$ height of water in the column referenced to the soil column to the soil outflow (cm), and $h_{i+l}$ is the next time of height for water referenced to soil outflow. Five different $\left(\frac{h_{i}}{h_{i+1}}\right)$ were used in each experiment, and data were linearly regressed to the determine $K$ from equation (2-7) 


\section{Chapter 3}

\section{RESULTS AND DISCUSSION}

\subsection{Particle Size Distributions}

Figure 3.1 shows PSDs for two mixtures of sediments with biochar to illustrate the difference between mass-based PSD and volume-based PSD. The black lines in Figure 3.1 represents PSD by mass and the blue lines PSD by volume. PSDs by mass are directly measured, while PSDs by volume are calculated using measured mass of each particle type, sediment or biochar, collected on each sieve and the envelope density of sediment and biochar. Because the envelope densities of the two materials are different, the mass-based PSDs are different from the volume-based PSDs. Volume-based PSD are shifted to the right in the Figure 3.1: because the unsieved biochar contains many large volume, but low-density particles, when plotted by volume versus mass PSDs show a greater number of larger particles. Because density of biochar is small with respect to sediment and biochar contains many elongated particles, the $d_{50}$ of volume-based PSD is larger than mass-based PSD, particularly for natural soil like SIL shown in Figure 3.1.B. 


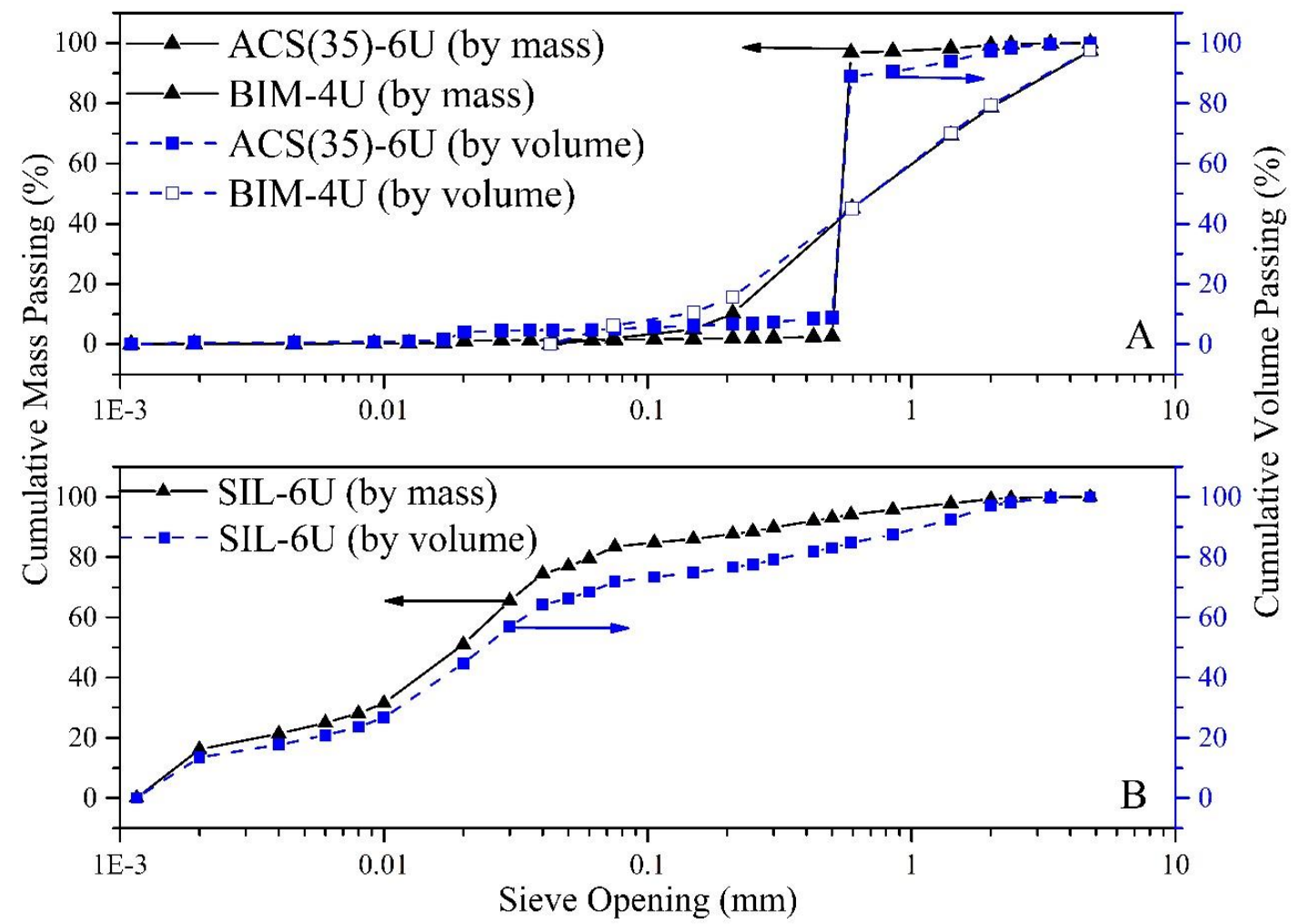

Figure 3.1: A Particle size distribution both by mass and volume for ACS (35)-6U, and BIM-4U. B Particle size distribution both by mass and volume for SIL-6U. Abbreviations are defined in Table 3.1.

Images of the sediments and the seven biochars are shown in the Appendix (Figures A.1-A.4). The corresponding mass-based PSDs of unmixed sediments and biochars are shown in Figures 3.2.A and 3.2.B, respectively. The mean particle size, $d_{50}$, of sediments increases from SIL, SAL, LOS, ACS (40), ACS (35), to BIM.

The red and black lines in Figure 3.2.B represent the entire rage of unsieved biochar particles (U) (red) or biochar sieved only to $<4.75 \mathrm{~mm}$ (U') (black). Approximately $88 \%$ of unsieved biochar falls within the sand fraction $(0.05-2 \mathrm{~mm})$. Small BC (S) sieved to $<0.841 \mathrm{~mm}$ includes $67 \%$ sand-sized particles $(>0.05 \mathrm{~mm})$. 
However, for the small BC (S') sieved to $0.001-0.059 \mathrm{~mm}$, only $3 \%$ of biochar particles are sand-sized. The large BC (L) (2-4.75 mm) and large BC (L') (0.841-4.75 $\mathrm{mm}$ ) possessed $100 \%$ and $27 \%$ gravel-sized particles (> $2 \mathrm{~mm})$, respectively.

Table 3-1 summarizes all experimental packings, where the dry bulk densities and envelop densities are given for each. As the biochar content increases, the dry bulk density and envelop density decrease.

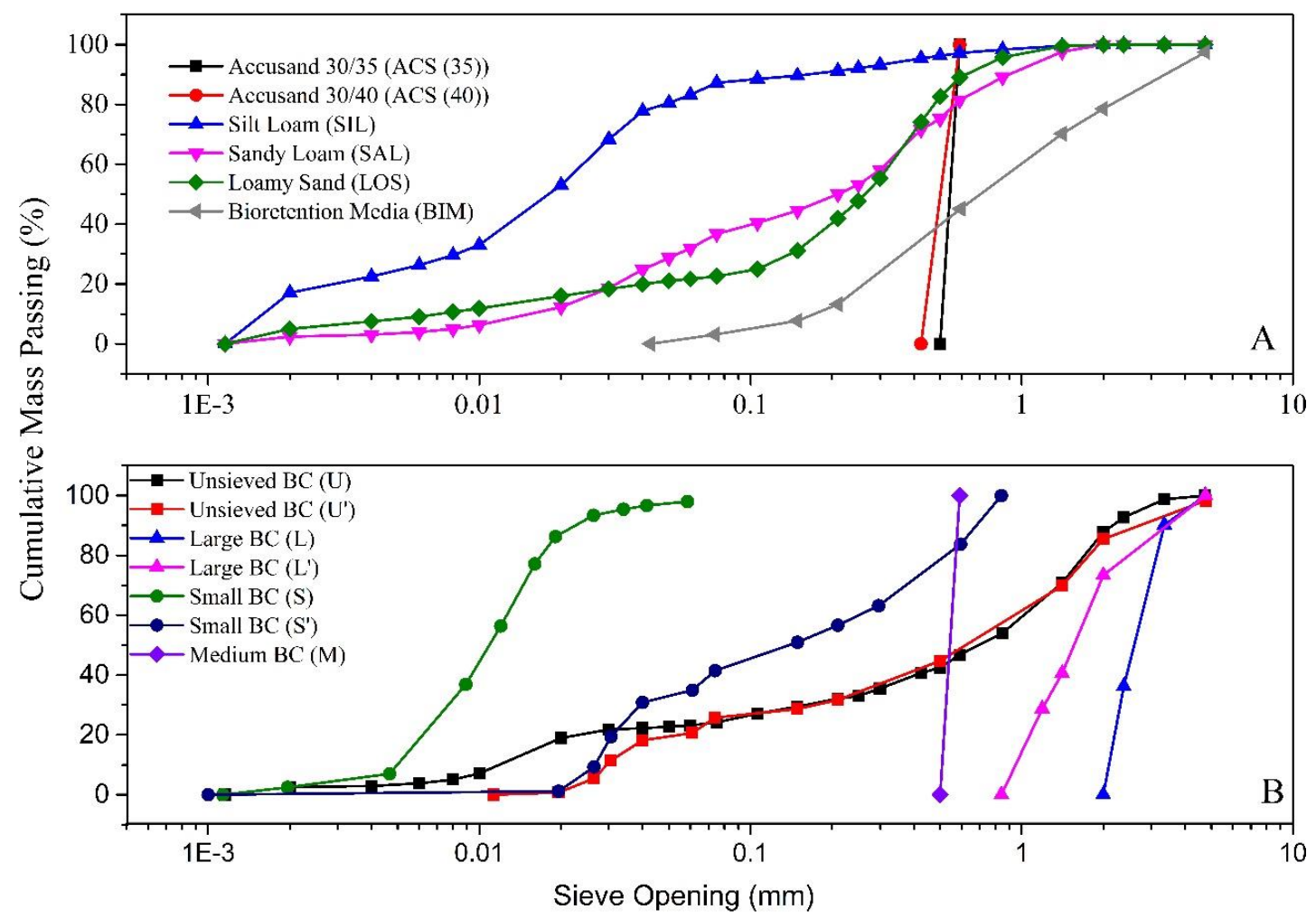

Figure 3.2: A Particle size distribution by mass for ACS (35), ACS (40), SIL, SAL, LOS, and BIM. B Particle size distribution by mass for different biochar samples. Abbreviations are defined in Table 3.1. 
Table 3.1: $\quad$ Properties of uniform sands, natural soil, and bioretention media with different size fractions of biochar.

\begin{tabular}{|c|c|c|c|c|c|}
\hline aSample & $\begin{array}{l}\text { Non-biochar } \\
\text { particle size } \\
(\mathrm{mm})\end{array}$ & $\begin{array}{l}\text { Biochar } \\
\text { particle size } \\
(\mathrm{mm})\end{array}$ & $\begin{array}{l}\text { Biochar } \\
\text { content } \\
(\mathrm{wt} \%)\end{array}$ & $\begin{array}{l}\text { Dry bulk } \\
\text { density }\left(\mathrm{g} / \mathrm{cm}^{3}\right)\end{array}$ & $\begin{array}{l}\text { Envelope } \\
\text { density }\left(\mathrm{g} / \mathrm{cm}^{3}\right)\end{array}$ \\
\hline $\operatorname{ACS}(30 / 35)$ & $0.5-0.595$ & - & 0 & $1.644 \pm 0.001$ & b2.665 \\
\hline $\operatorname{ACS}(30 / 35)-6 U$ & $0.5-0.595$ & $<4.75$ & 6 & $1.256 \pm 0.001$ & $2.140 \pm 0.001$ \\
\hline $\operatorname{ACS}(30 / 35)-6 \mathrm{~L}$ & $0.5-0.595$ & $2-4.75$ & 6 & $1.212 \pm 0.002$ & $2.140 \pm 0.001$ \\
\hline $\operatorname{ACS}(30 / 35)-6 \mathrm{M}$ & $0.5-0.595$ & $0.5-0.59$ & 6 & $1.131 \pm 0.001$ & $2.140 \pm 0.001$ \\
\hline $\operatorname{ACS}(30 / 35)-6 S$ & $0.5-0.595$ & $0.001-0.059$ & 6 & $1.131 \pm 0.001$ & $2.140 \pm 0.001$ \\
\hline ACS $(30 / 40)$ & $0.425-0.595$ & - & 0 & $1.600 \pm 0.001$ & $\mathrm{~b}_{2} .665$ \\
\hline $\operatorname{ACS}(30 / 40)-4 S^{\prime}$ & $0.425-0.595$ & $<0.841$ & 4 & $1.736 \pm 0.001$ & $2.280 \pm 0.001$ \\
\hline $\operatorname{ACS}(30 / 40)-4 U^{\prime}$ & $0.425-0.595$ & $<2$ & 4 & $1.533 \pm 0.001$ & $2.280 \pm 0.001$ \\
\hline $\operatorname{ACS}(30 / 40)-4 L^{\prime}$ & $0.425-0.595$ & $0.841-4.75$ & 4 & $1.412 \pm 0.001$ & $2.280 \pm 0.001$ \\
\hline SIL & $<2$ & - & 0 & $1.173 \pm 0.001$ & $2.658 \pm 0.001$ \\
\hline SIL-2U & $<2$ & $<4.75$ & 2 & $1.401 \pm 0.001$ & $2.458 \pm 0.001$ \\
\hline SIL-6U & $<2$ & $<4.75$ & 6 & $1.321 \pm 0.001$ & $2.136 \pm 0.001$ \\
\hline SAL & $<2$ & - & 0 & $1.161 \pm 0.001$ & $2.591 \pm 0.001$ \\
\hline SAL-2U & $<2$ & $<4.75$ & 2 & $1.462 \pm 0.001$ & $2.402 \pm 0.001$ \\
\hline SAL-6U & $<2$ & $<4.75$ & 6 & $1.376 \pm 0.001$ & $2.095 \pm 0.001$ \\
\hline LOS & $<2$ & - & 0 & $1.205 \pm 0.001$ & $2.667 \pm 0.001$ \\
\hline LOS-2U & $<2$ & $<4.75$ & 2 & $1.551 \pm 0.001$ & $2.465 \pm 0.001$ \\
\hline LOS-6U & $<2$ & $<4.75$ & 6 & $1.432 \pm 0.001$ & $2.141 \pm 0.001$ \\
\hline BIM & $<2$ & - & 0 & $1.204 \pm 0.001$ & $1.924 \pm 0.001$ \\
\hline BIM-4S' & $<2$ & $<0.841$ & 4 & $1.515 \pm 0.001$ & $1.738 \pm 0.001$ \\
\hline BIM-4U' & $<2$ & $<2$ & 4 & $1.261 \pm 0.001$ & $1.738 \pm 0.001$ \\
\hline BIM-4L' & $<2$ & $0.841-4.75$ & 4 & $1.289 \pm 0.001$ & $1.738 \pm 0.001$ \\
\hline Unsieved Biochar & - & $<4.75$ & 100 & $1.048 \pm 0.001$ & $0.520 \pm 0.027$ \\
\hline
\end{tabular}

a ACS, SIL, SAL, LOS, BIM are abbreviations for Accusand, silt loam, sandy loam, loamy sand, and bioretention media, respectively. 30/35 and 30/40 contain particles between US Std. \#30 and \#35, or US Std. \#30 and \#40 sieves. U, L, M, and S represent unsieved, large, medium and small biochar. U', L', and S' represent unsieved biochar smaller $2 \mathrm{~mm}$, large biochar between 0.841-4.76 mm, and small biochar smaller $0.841 \mathrm{~mm}$

${ }^{b}$ The value is from (M. H. Schroth 1996). ACS (30/40) has the envelope density with $\operatorname{ACS}(30 / 35)$. 


\subsection{Saturated Hydraulic Conductivity}

The saturated hydraulic conductivity $(K)$ of sediments with and without biochar are reported in Table 3.2, along with interporosities of all sediment/biochar mixtures. Two biochar properties significantly influenced $K$ : particle size and quantity of biochar amendment. A second factor influencing $K$ was the PSD of the sediment. Measured $K$ of the unamended media spanned four orders of magnitude: 820, 510 , 0.371, 2.55, 5.99, and 77.6 cm/h for Accusand 30/35 (ACS (35)), Accusand 30/40 (ACS (40)), silt loam (SIL), sandy loam (SAL), loamy sand (LOS), and bioretention media (BIM), respectively (Table 3.2). 
Table 3.2: $\quad$ Physical properties of column packings and measured and K-C model predicted saturated hydraulic conductivities

\begin{tabular}{lccccccc}
\hline \multicolumn{1}{c}{ Sediment } & ${ }^{\mathrm{a} N}$ & $\begin{array}{c}S_{m} \\
\left(\mathrm{~m}^{2} / \mathrm{kg}\right)\end{array}$ & $\begin{array}{c}S_{v} \\
\left(\mathrm{~m}^{2} / \mathrm{m}^{3}\right)\end{array}$ & $\begin{array}{c}{ }^{\mathrm{b}} \text { Total } \\
\text { porosity }\end{array}$ & $\begin{array}{c}\text { Interp } \\
\text { orosity }\end{array}$ & $\begin{array}{c}{ }^{\mathrm{c}} \mathrm{Pred} K \\
(\mathrm{~cm} / \mathrm{hr})\end{array}$ & $\begin{array}{c}{ }^{\mathrm{d}} \mathrm{Meas} K \\
(\mathrm{~cm} / \mathrm{hr})\end{array}$ \\
\hline ACS (35) & 2 & $4.15 \mathrm{E}+00$ & $1.10 \mathrm{E}+04$ & 0.383 & 0.383 & $8.52 \mathrm{E}+02$ & $820 \pm 90$ \\
ACS (35)-6U & 2 & $9.06 \mathrm{E}+00$ & $6.10 \mathrm{E}+04$ & 0.485 & 0.412 & $5.80 \mathrm{E}+01$ & $130 \pm 20$ \\
ACS (35)-6L & 2 & $2.70 \mathrm{E}+00$ & $5.09 \mathrm{E}+03$ & 0.503 & 0.433 & $5.73 \mathrm{E}+03$ & $92 \pm 5$ \\
${ }^{\text {ACS (35)-6L }}$ & 2 & $2.70 \mathrm{E}+00$ & $5.09 \mathrm{E}+03$ & 0.537 & 0.471 & $8.48 \mathrm{E}+03$ & $370 \pm 30$ \\
ACS (35)-6M & 2 & $5.17 \mathrm{E}+00$ & $1.10 \mathrm{E}+04$ & 0.536 & 0.471 & $2.14 \mathrm{E}+03$ & $323 \pm 9$ \\
ACS (35)-6S & 2 & $2.27 \mathrm{E}+01$ & $1.65 \mathrm{E}+05$ & 0.344 & 0.251 & $7.33 \mathrm{E}-01$ & $3.44 \pm 0.13$ \\
ACS (40) & 2 & $4.25 \mathrm{E}+00$ & $1.13 \mathrm{E}+04$ & 0.349 & 0.349 & $5.54 \mathrm{E}+02$ & $510 \pm 10$ \\
ACS (40)-4S' & 2 & $5.04 \mathrm{E}+00$ & $1.40 \mathrm{E}+04$ & 0.389 & 0.330 & $2.88 \mathrm{E}+02$ & $41.0 \pm 0.3$ \\
ACS (40)-4U' & 2 & $4.89 \mathrm{E}+00$ & $1.24 \mathrm{E}+04$ & 0.438 & 0.383 & $6.71 \mathrm{E}+02$ & $136.7 \pm 1.0$ \\
ACS (40)-4L' & 2 & $4.87 \mathrm{E}+00$ & $1.00 \mathrm{E}+04$ & 0.533 & 0.487 & $3.07 \mathrm{E}+03$ & $324 \pm 2$ \\
SIL & 2 & $3.91 \mathrm{E}+02$ & $1.04 \mathrm{E}+06$ & 0.473 & 0.473 & $2.47 \mathrm{E}-01$ & $0.371 \pm 0.010$ \\
SIL-2U & 2 & $4.17 \mathrm{E}+02$ & $9.62 \mathrm{E}+05$ & 0.488 & 0.462 & $2.59 \mathrm{E}-01$ & $0.33 \pm 0.02$ \\
SIL-6U & 2 & $4.65 \mathrm{E}+02$ & $8.37 \mathrm{E}+05$ & 0.523 & 0.455 & $3.18 \mathrm{E}-01$ & $0.256 \pm 0.002$ \\
SAL & 2 & $8.30 \mathrm{E}+01$ & $2.15 \mathrm{E}+05$ & 0.436 & 0.436 & $3.95 \mathrm{E}+00$ & $2.55 \pm 0.08$ \\
SAL-2U & 2 & $8.96 \mathrm{E}+01$ & $2.15 \mathrm{E}+05$ & 0.453 & 0.427 & $3.59 \mathrm{E}+00$ & $1.00 \pm 0.05$ \\
SAL-6U & 2 & $1.03 \mathrm{E}+02$ & $2.15 \mathrm{E}+05$ & 0.494 & 0.424 & $3.49 \mathrm{E}+00$ & $1.15 \pm 0.08$ \\
LOS & 2 & $1.27 \mathrm{E}+02$ & $3.38 \mathrm{E}+05$ & 0.418 & 0.418 & $1.33 \mathrm{E}+00$ & $5.99 \pm 0.06$ \\
LOS-2U & 2 & $1.36 \mathrm{E}+02$ & $3.26 \mathrm{E}+05$ & 0.446 & 0.419 & $1.43 \mathrm{E}+00$ & $2.42 \pm 0.04$ \\
LOS-6U & 2 & $1.55 \mathrm{E}+02$ & $3.07 \mathrm{E}+05$ & 0.507 & 0.437 & $1.95 \mathrm{E}+00$ & $7.02 \pm 0.06$ \\
BIM & 2 & $8.11 \mathrm{E}+00$ & $1.56 \mathrm{E}+04$ & 0.213 & 0.213 & $4.48 \mathrm{E}+01$ & $77.6 \pm 0.4$ \\
BIM-4S' & 2 & $9.14 \mathrm{E}+00$ & $2.12 \mathrm{E}+04$ & 0.323 & 0.274 & $6.25 \mathrm{E}+01$ & $131 \pm 5$ \\
BIM-4U' & 2 & $7.97 \mathrm{E}+00$ & $1.82 \mathrm{E}+04$ & 0.308 & 0.258 & $6.62 \mathrm{E}+01$ & $315.0 \pm 1.9$ \\
BIM-4L & 2 & $8.33 \mathrm{E}+00$ & $1.56 \mathrm{E}+04$ & 0.437 & 0.397 & $4.94 \mathrm{E}+02$ & $243 \pm 3$ \\
\hline
\end{tabular}

${ }^{a} \mathrm{~N}$ is number of independent sample measurements

${ }^{b}$ the standard error for total porosity and interporosity are all 0.001 .

${ }^{c}$ Predicted saturated hydraulic conductivity $(\mathrm{K})$ calculated with K-C model using Sv and interporosity (equation (3-3))

${ }^{\mathrm{d}}$ Measured $K$

${ }^{\mathrm{e}}$ Accusand amended with large biochar (ACS (35)-6L), but the bulk density is equal to $1.131 \pm 0.001(\mathrm{~g} / \mathrm{cm} 3)$, same with the bulk density of ACS (35)-6M. 
In Figure 3.3.A, $K$ of biochar-amended sediment are plotted against interporosity. Data indicate that as interporosity increases, $K$ increases. For example, application of $6 \%$ unsieved biochar reduced interporosity by $3.5 \%$ and $2.5 \%$ for silt loam (SIL) and sandy loam (SAL), respectively, which reduced $K$ by $31 \%$ and $55 \%$ for these two media. On the other hand, application of $6 \%$ unsieved biochar increased interporosity and $K$ by $4.6 \%$ and $17 \%$, respectively, in loamy sand (LOS). For bioretention media (BIM), application of $4 \%$ biochar of different sizes increased interporosity by $22 \%, 29 \%$, and $87 \%$, which corresponded to increases in $K$ of $306 \%$, $68 \%$, and $213 \%$ in BIM-4U, BIM-4S, and BIM-4L, respectively.

Increased interporosity did not always increase $K$ for biochar-amendment of Accusands, though. When biochar particles were large, interporosity increased from 0.383 to 0.434 when $6 \%$ large biochar (L) was amended to ACS (35), but $K$ decreased from 820 to $92 \mathrm{~cm} / \mathrm{h}$. Similar results occurred when unsieved biochar (U or U') were amended to ACS (35) and ACS (40): interporosity increased with biochar amendment, but $K$ decreased. It seems likely that the shape, surface roughness, and elongated form of large biochar particles increased the tortuosity of flow paths sufficiently that even with increased interporosity resistance to water flow increased. Similar results did not occur when small biochar particles were amended to Accusand: when biochar S was amended to ACS (35) and biochar S' amended to ACS (40), interporosities decreased for both mixtures by $34 \%$ and $5 \%$, respectively, and corresponding $K$ decreased by $99 \%$ and $92 \%$. Based on these observations, $K$ appears to be influenced by volume of pores between particles, interporosity and pore structure, which varies with size of biochar particles amended. 

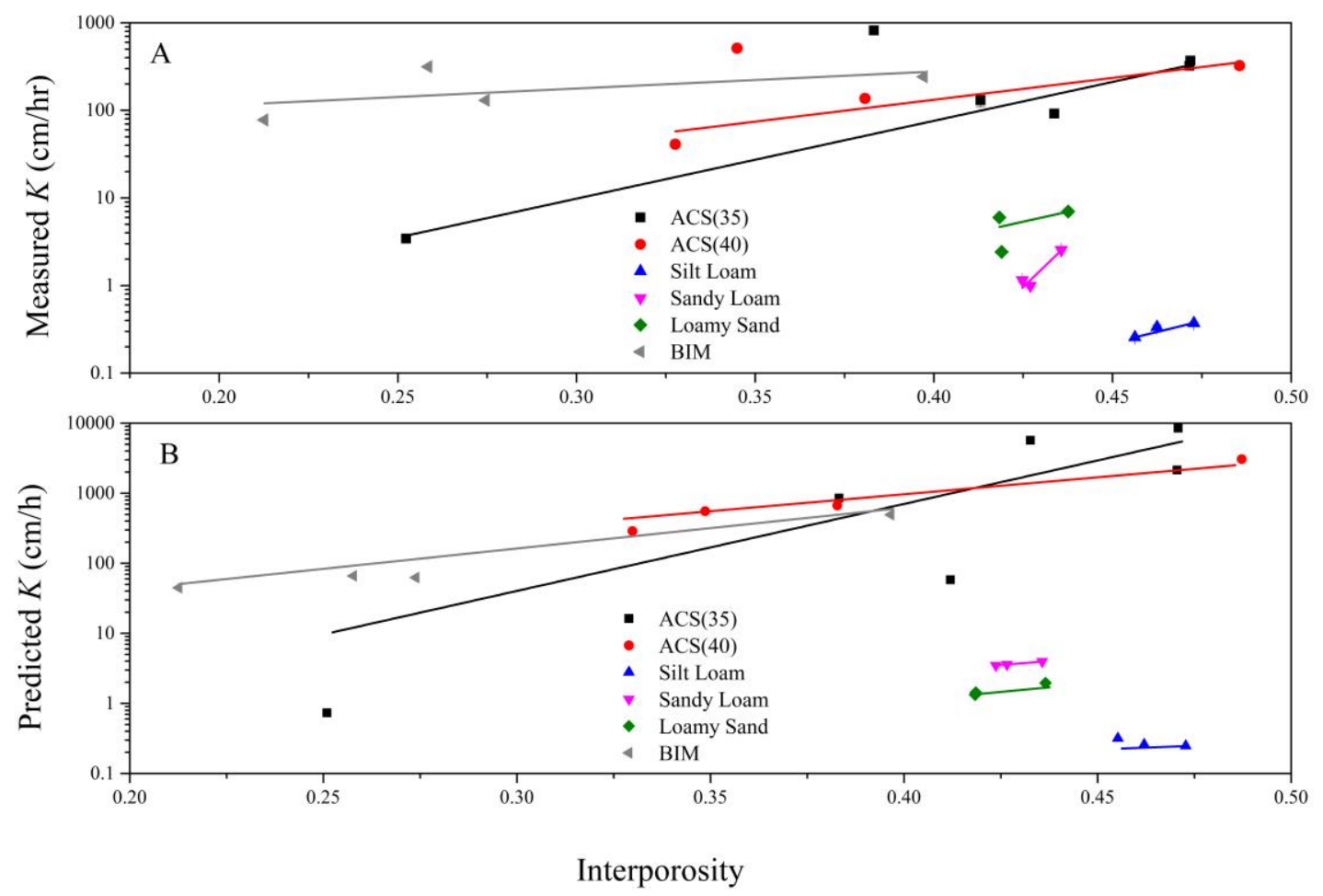

Figure 3.3: The relationship between interporosity and measured $K(\mathrm{~A})$, and interporosity and K-C model predicted $K$ (equation 3-3) (B). Linear regressions were conducted weighting the data by the inverse of the squared standard error of measured $K$. Error bars in the plots are too small to be visible.

\subsection{Kozeny-Carmen Model}

Many models have been developed to predict $K$ (Fair 1933, Carman 1937,

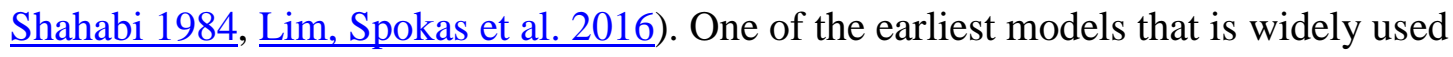
today was proposed by Kozeny (1927) and later modified by Carman $(1937,1956)$

$$
K=C \frac{g \rho_{w}}{\mu_{w}} \frac{1}{\left(S_{m} \times \rho_{e}\right)^{2}} \frac{\phi^{3}}{(1-\phi)^{2}}
$$


where $\mu_{w}$ is the dynamic viscosity of water $(\mathrm{kg} / \mathrm{m} / \mathrm{s}), \phi$ is porosity (dimensionless), $\rho_{w}$ it the density of water $\left(\mathrm{kg} / \mathrm{m}^{3}\right)$, and $g$ is the gravitational constant $\left(\mathrm{m} / \mathrm{s}^{2}\right) . S_{m}$ is the specific surface area $\left(\mathrm{m}^{2} / \mathrm{kg}\right)$, and $C$ is a dimensionless factor that accounts for shape and tortuosity of flow channels. The Kozeny-Carmen (K-C) model was developed considering a porous material as an assembly of capillary tubes for which NavierStokes equations describe flow (Dolzyk and Chmielewska 2014). The value of $C=$ 0.20 includes simultaneously the notion of equivalent capillary channel cross-section and tortuosity (Chapuis and Aubertin 2003, Eibisch, Durner et al. 2015). The value of $C_{K C}=1 / C=4.8 \pm 0.3(\underline{\text { W. David Carrier III 2003) }}$ ) for uniform spheres, reported by Carman (1956), is usually taken to be 5 and thus $C=0.2$. The value of $C$ has been reported between $1 / 6$ and $1 / 2.4$, and $1 / 5$ is generally employed for unconsolidated porous media (Wyllie 1955). In this work with unconsolidated porous media, $C=0.2$ was assumed.

\subsubsection{Envelope Density and Interporosity}

While biochar has significant internal porosity that affects total sample porosity, the micron and sub-micron sized pores inside biochar will have negligible impact on water permeability: biochar intrapores are too small to transmit water effectively. Thus, it is postulated that water primarily passes through interpores between particles of biochar-amended sediment. In this case, the total porosity in the $\mathrm{K}-\mathrm{C}$ model is replaced with the interporosity

$$
K=C \frac{g \rho_{w}}{\mu_{w}} \frac{1}{\left(S_{m} \times \rho_{e}\right)^{2}} \frac{\phi_{\text {inter }}^{3}}{\left(1-\phi_{\text {inter }}\right)^{2}}
$$

The specific surface area in equations (3-1) and (3-2) is a measure of the outer particle surface area per unit mass of particles. Because of the markedly different 
densities of biochar and sediment particles, it is postulated that a better measure of surface area is one defined based on envelope volume of particles, not particle mass. In this case, the $\mathrm{K}-\mathrm{C}$ equation is written

$$
K=C \frac{g \rho_{w}}{\mu_{w}} \frac{1}{S_{v}^{2}} \frac{\phi_{\text {inter }}^{3}}{\left(1-\phi_{\text {inter }}\right)^{2}}
$$

where $S_{v}$ is the specific surface area by volume $\left(\mathrm{m}^{2} / \mathrm{m}^{3}\right)$. As will be shown below, with this definition it is possible to separately compute the influence of biochar and sediment particles on $S_{v}$. In the analysis of $K$ data, equations (3-1), (3-2), and (3-3) were used.

\subsubsection{Estimation of Specific Surface Area}

The specific surface area of sediment and biochar is a critical parameter in the K-C model. This parameter may be estimated assuming particles are spheres or cubes (Legare 1992). Other approaches result in estimates of $S_{m}$ or $S_{v}$ by introducing the shape, roughness, or projection factors (Chapuis 2012). If biochar particles are assumed spheres, then $S_{m}$ for a single spherical particle is computed from

$$
S_{m}=\frac{\text { area }}{\text { mass }}=\frac{\pi D^{2}}{\pi D^{3} / 6 \times \rho_{e}}=\frac{6}{D \times \rho_{e}}
$$

As shown in Figure A.1, though, the large biochar particles used in this work had elongated shapes. If particles are assumed to be rectangular in shape, then when sieved to diameter $d$ (sieve opening size) they could, for example, have height $0.25 d$, width $d$, and length $2 d$. In this case, $S_{m}$ for a single, rectangular-shaped particle is computed from equation (3-4), replacing “6” with “ 11 ”.

For samples with a range of sizes, $S_{m}$ has been estimated from (Legare 1992).

$$
S_{m}=\frac{6}{\rho_{e}} \sum_{i=1}^{n-1} \frac{P_{N o . D}-P_{N o . d}}{\sqrt{D_{D} \times D_{d}}}
$$


where $P_{d_{i}}$ is the percentage by weight of particles of diameter $d_{i}, P_{d_{i+1}}$ is the percentage by weight of particles that are the next size smaller $d_{i+1}, i$ is an index starting from the largest particle size to the smallest, and $\mathrm{n}$ is the number of particle size divisions. In the method of (Legare 1992), an equivalent size, $d_{e q}$, must be defined for all particles smaller than the minimum size of the particle size distribution

$$
d_{e q}^{2}=\frac{1}{D_{\min }} \int_{0}^{D_{\min }} y^{2} d y=\frac{D_{\min }^{2}}{3}
$$

Equation (3-5) was used here to estimate the smallest $d_{i}$ in equation (3-5).

To calculate the specific surface area by volume, $S_{v}$, the surface area and volume of particles in each size class $i, S_{a i}$ and $S_{V i}$, are determined using the envelope density of the sediment, $\rho_{e_{s}}$, and biochar, $\rho_{e_{B C}}$,

$$
\begin{aligned}
& S_{a i}=\left(\frac{m_{s i}}{\rho_{e_{S}}}+\frac{m_{B C i}}{\rho_{e_{B C}}}\right) \frac{6}{\sqrt{d_{i} d_{i-1}}} \\
& S_{V i}=\left(\frac{m_{s i}}{\rho_{e_{S}}}+\frac{m_{B C i}}{\rho_{e_{B C}}}\right)
\end{aligned}
$$

$m_{S i}$ and $m_{B C i}$ are the mass of soil and biochar in each sieve or particle size class, respectively. With these, $S_{v}$ is determined from

$$
S_{v}=\frac{\sum_{i=1}^{n} S_{a i}}{\sum_{i=1}^{n} S_{V i}}
$$

\subsection{Lim Model}

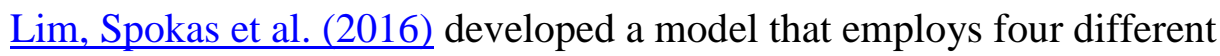
pedotransfer functions (PTF) based on sand and clay size fractions of biochar to predict $K$ of biochar-amended soils. Biochar amended to a given soil is assumed to alter the sand or clay size fraction, depending on the PSD of the biochar. Their approach averages the results from the four PTFs to obtain an estimated saturated hydraulic conductivity. The soils in Lim's study were amended with pine chip, 
hardwood chip, oat husk, and hardwood pellet biochar, all of which were unsieved and had different PSDs. The Lim model was developed using their experimental data, and then evaluated using published $K$ data for other biochar-amended soils.

In the Lim model, biochar must be classified as either sand texture $(>0.5 \mathrm{~mm})$, silt texture $(0.002-0.5 \mathrm{~mm})$, or clay texture $(<0.002 \mathrm{~mm})$. The biochars used in this study were classified in these categories. For unsieved biochar (U and U') that contained particles in all three textural classes, biochar was classified as sand texture, since $57 \%$ of unsieved biochar was in the sand texture range, $40 \%$ was silt texture, and $3 \%$ clay texture.

\subsection{Statistical Analysis}

To quantitatively compare the K-C and Lim model predictions, the raw data is converted into logarithmic (the base is 10) data for all the statistical analyses. Data are $\log$ transformed, given the several orders of magnitude variation of $K$ for the data in this work. The following parameters are then defined

$$
\begin{aligned}
\Delta K & =\frac{\log \left(K_{p}\right)-\log \left(K_{m}\right)}{\log \left(K_{m}\right)} \\
\Delta K_{p} & =\frac{\log \left(K_{p}\right)-\log \left(K_{p_{c}}\right)}{\log \left(K_{p_{c}}\right)} \\
\Delta K_{m} & =\frac{\log \left(K_{m}\right)-\log \left(K_{m_{c}}\right)}{\log \left(K_{m_{c}}\right)}
\end{aligned}
$$

where $K_{p}$ and $K_{p_{c}}$ are predicted $K$ values from models for biochar-amended or unamended (control) sediment, respectively, and $K_{m}$ and $K_{m_{c}}$ are measured $K$ values for amended or control sediment. $\Delta K$ is the relative error of the model prediction in $\log$ space. $\Delta K_{p}$ is the relative model-predicted change in log $K$ from biochar 
amendment, and $\Delta K_{m}$ is the relative measured change in $\log K$ from biochar amendment. For a good model, $\Delta K$ is small and $\Delta K_{p}$ is similar to $\Delta K_{m}$.

To quantify the model goodness of fit, mean absolute error $(M A E)$ and modified coefficient of efficiency $\left(E_{1}\right)$ were selected to analyze the data (Legates and McCabe 1999). $E_{1}$ overcomes the limitations of correlation-based measures for assessing relative model error (Legates and McCabe 1999). $M A E$, on the other hand, is a reasonable measure of model absolute error: because of the slight bias in root mean square error $(R M S E)$ when large outliers are present, $M A E$ is slightly preferred over $R M S E$ (Legates and McCabe 1999). $M A E$ and $E_{1}$ are computed from

$$
\begin{aligned}
& M A E=\frac{\sum_{i=1}^{N}\left|O_{i}-P_{i}\right|}{N} \\
& E_{1}=1.0-\frac{\sum_{i=1}^{N}\left|O_{i}-P_{i}\right|}{\sum_{i=1}^{N}\left|O_{i}-\bar{O}\right|}
\end{aligned}
$$

where $O_{i}$ is either $\log \left(K_{m}\right)$ or $\log \left(K_{m_{c}}\right) ; P_{i}$ is either $\log \left(K_{p}\right)$ or $\log \left(K_{p_{c}}\right)$ predicted by K-C or Lim models, and $\bar{O}$ is the mean of measured $K$. Alternatively, $O_{i}$ is $\Delta K_{m} ; P_{i}$ is $\Delta K_{p}$ predicted by K-C or Lim models, and $\bar{O}$ is the mean of $\Delta K_{m}$.

$M A E$ describes the difference between the model predictions and observations in the log-transformed variable. $E_{1}$ is a dimensionless value used to evaluate the relative performance of models and ranges from minus infinity to 1.0, with higher values indicating better model agreement (Legates and McCabe 1999). Table A.1 and A.2 (in the Appendix) illustrate more information about the differences between the K-C and Lim models based on $M A E$ and $E_{l}$.

\subsection{Model Predictions}

Predicted $K$ using the $\mathrm{K}-\mathrm{C}$ model are shown in Figure 3.4 and Table 3.2. Model predictions of $K$ for natural soil and bioretention media are within a factor of 3 
of measured $K$. However, the prediction of ACS (35)-6L, ACS (35)-6 L*, ACS (35)6M, ACS (40)-6S', and ACS (40)-6L' are more than a factor of 3 different from measured values. For example, the prediction of ACS (35)-6L is a factor of 60 greater than measured $K$. One hypothesis about why the $\mathrm{K}-\mathrm{C}$ model performed poorly for biochar-amended sand is that the biochar particles were not uniformly mixed and segregation occurred (Lei and Zhang 2013). Future work is necessary to test this hypothesis.
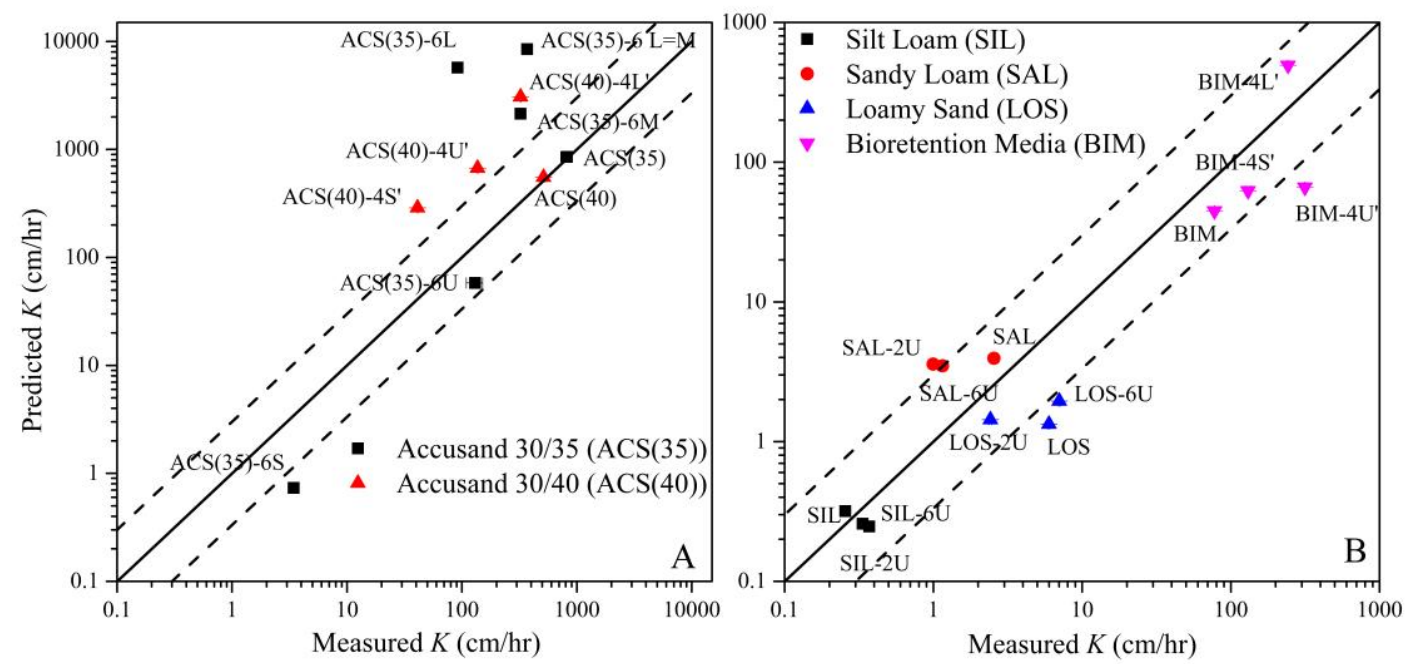

Figure 3.4: A. and B. Predicted versus measured $K$ computed using equation (3-3) for uniform sands, natural soils and bioretention media. Error bars are \pm one standard error and most area so small as not to be visible. Dashed lines represent $3 \mathrm{X}$ differences between model-predicted and measured $K$.

Figure 3.5 shows the Lim model predictions: this model worked well for natural soils, but poorly for sands and bioretention media. The trend of $\mathrm{K}-\mathrm{C}$ model predictions is similar to that of the data. Although the Lim model predicted $K$ in uniform sand with 
different size of biochar to the correct order of magnitude, the prediction of $K$ for Accusand amended with different sizes of biochar are all identical.
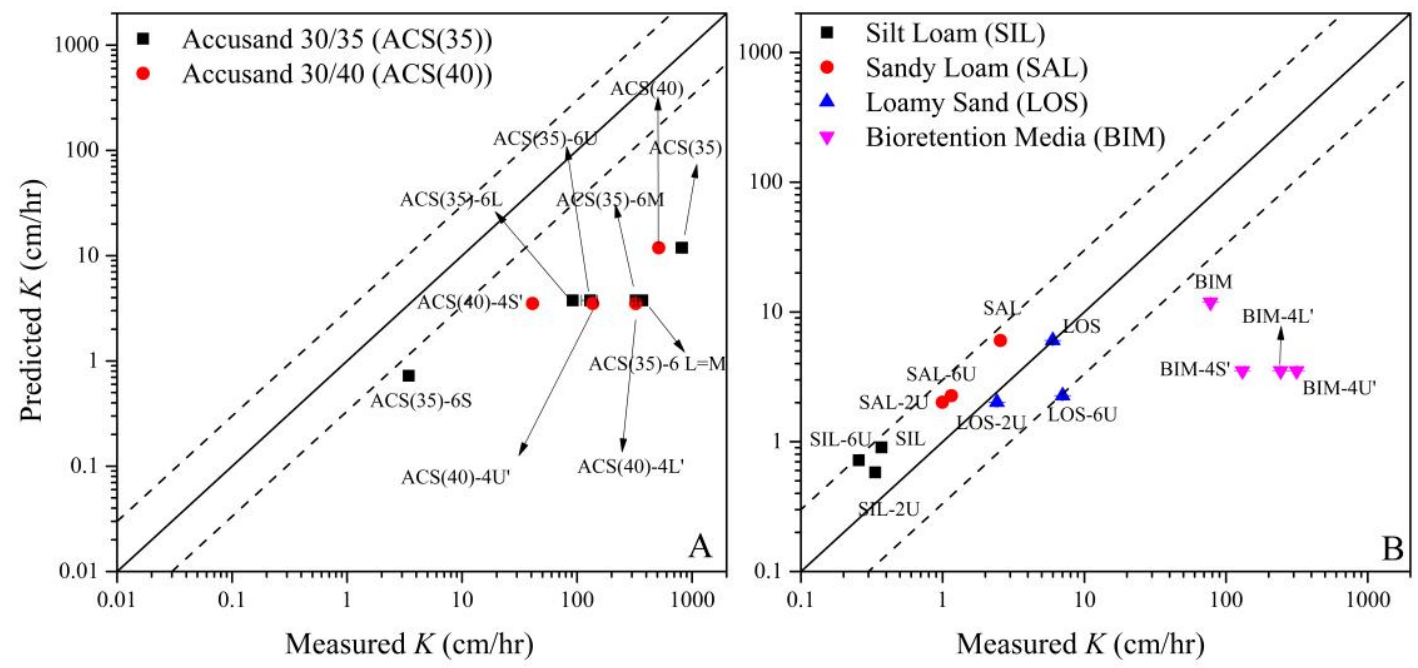

Figure 3.5: Predicted $K$ from the Lim model versus measured $K$. Error bars are \pm one standard error and most are so small as not to be visible. Dashed lines represent $3 \mathrm{X}$ differences between model-predicted and measured $K$.

Figures 3.4 and 3.5 illustrate the absolute model errors. The relative errors re shown in Table 3.3 (using equations (3-10) and (3-11)). Here, goodness of fit occurs when the sign and magnitude of $\Delta K_{m}$ and $\Delta K_{p}$ are similar: in this occurs, the model predicts the relative change in $K$ because of biochar amendment accurately. From Table 3.3 results, the $\mathrm{K}-\mathrm{C}$ model resulted in good predications for natural soils and bioretention media, but not for Accusand with different size of biochar, especially for Accusand amended with large biochar. Although the signs of $\Delta K_{p}$ matches those for $\Delta K_{m}$ when the Lim model is applied to Accusand samples, predicted $K$ for Accusand with different size biochar (except ACS (35)-6S) are identical: $3.76 \mathrm{~cm} / \mathrm{h}$ for ACS 
(35), and $3.52 \mathrm{~cm} / \mathrm{h}$ for ACS (40), respectively. The prediction of sediment amended by large biochar particles is often significantly in error, and as result $\Delta K_{m}$ and $\Delta K_{p}$ differ significantly for these sediments. 
Table 3.3: $\Delta K_{m}$ and $\Delta K_{p}$ using $\mathrm{K}-\mathrm{C}$ and Lim models.

\begin{tabular}{|c|c|c|c|c|c|c|}
\hline \multirow{3}{*}{ Sediments } & \multirow{3}{*}{$\Delta K_{m}$} & \multicolumn{5}{|c|}{${ }^{\mathrm{a}} \Delta K_{p}$} \\
\hline & & \multicolumn{4}{|c|}{ K-C Model } & \multirow{2}{*}{$\begin{array}{l}\text { Lim } \\
\text { Mode }\end{array}$} \\
\hline & & $\mathrm{TP} \& \mathrm{M}$ & IP \& M & $\mathrm{TP}$ and $\mathrm{V}$ & IP and V & \\
\hline ACS (35) & - & - & - & - & - & - \\
\hline ACS (35)-6U & -0.27 & 0.01 & -0.12 & -0.33 & -0.46 & -0.47 \\
\hline ACS (35)-6L & -0.33 & 0.39 & 0.27 & 0.43 & 0.31 & -0.47 \\
\hline $\operatorname{ACS}(35)-6 L^{*}$ & -0.12 & 0.44 & 0.33 & 0.48 & 0.37 & -0.47 \\
\hline $\operatorname{ACS}(35)-6 \mathrm{M}$ & -0.14 & 0.25 & 0.14 & 0.25 & 0.14 & -0.47 \\
\hline ACS (35)-6S & -0.82 & -0.48 & -0.68 & -0.85 & -1.04 & -1.13 \\
\hline $\operatorname{ACS}(40)$ & - & - & - & - & - & - \\
\hline ACS (40)-4S' & -0.40 & 0.08 & -0.04 & 0.02 & -0.10 & -0.49 \\
\hline ACS (40)-4U' & -0.21 & 0.17 & 0.07 & 0.14 & 0.03 & -0.49 \\
\hline ACS (40)-4L' & -0.07 & 0.32 & 0.24 & 0.35 & 0.27 & -0.49 \\
\hline SIL & - & - & - & - & - & - \\
\hline SIL-2U & 0.10 & -0.16 & 0.05 & -0.25 & -0.04 & 4.42 \\
\hline SIL-6U & 0.37 & -0.49 & 0.05 & -0.74 & -0.19 & 2.27 \\
\hline SAL & - & - & - & - & - & - \\
\hline SAL-2U & -1.00 & 0.16 & -0.07 & 0.16 & -0.07 & -0.61 \\
\hline SAL-6U & -0.85 & 0.50 & -0.09 & 0.51 & -0.08 & -0.55 \\
\hline LOS & - & - & - & - & - & - \\
\hline LOS-2U & -0.51 & 1.20 & 0.07 & 1.40 & 0.27 & -0.61 \\
\hline LOS-6U & 0.09 & 3.61 & 0.84 & 4.13 & 1.36 & -0.55 \\
\hline BIM & - & - & - & - & - & - \\
\hline BIM-4S' & 0.12 & 0.42 & 0.24 & 0.27 & 0.08 & -0.49 \\
\hline BIM-4U' & 0.32 & 0.45 & 0.25 & 0.30 & 0.11 & -0.49 \\
\hline BIM-4L' & 0.26 & 0.78 & 0.60 & 0.75 & 0.63 & -0.49 \\
\hline
\end{tabular}

a TP, IP, M, V represent total porosity, interporosity, $S_{m}$ by mass, and $S_{v}$ by volume, respectively, in the $\mathrm{K}-\mathrm{C}$ model.

Results using the $M A E$ and $E_{1}$ evaluation tools on log-transformed $K$ are reported in Tables 3.4 and 3.5. Over all sediments, the K-C model has smaller MAE and larger $E_{l}$ for calculations using interporosity and $S_{v}$ in equation (3-3) (Table 3.4 and Table 3.5). If samples with large biochar particles (ACS (35)-6L, ACS (35)-6L*, ACS (40)-4L and BIM-4L) are excluded, the K-C model with total porosity and $S_{v}$ is 
best overall. Although the values of $M A E$ and $E_{l}$ for the natural soils show that the Lim model is better for these sediments, the difference between $\mathrm{K}-\mathrm{C}$ (with interporosity and $S_{v}$ in equation (3-3)) and Lim models is very small (0.339 vs 0.292 for $E_{1}$ in the Tables 3.4 and 3.5). Thus, when predicting $K$ for either biochar-amended or unamended sediments in this study, the $\mathrm{K}-\mathrm{C}$ model is best using interporosity and $S_{v}$ in equation (3-3).

When $\Delta K_{m}$ is predicted, though, the Lim model is best model for all sediments since $M A E$ is smaller and larger $E_{1}$ (Tables 3.6 and Figure 3.6). The results are also shown when samples with large size biochar particles (ACS (35)-6L, ACS (35)-6L*, ACS (40)-4L and BIM-4L) are excluded, which also show that the Lim model is best overall for all sediments (Table 3.6). The K-C model is only best for the bioretention media (Tables 3.6 and 3.7). 
Table 3.4: The $M A E$ and $E_{1}$ for K-C and Lim model predictions of $\log (K)$. The shaded numbers represent the best prediction for each row.

\begin{tabular}{|c|c|c|c|c|c|}
\hline \multirow{2}{*}{$M A E$} & \multicolumn{4}{|c|}{ K-C Model } & \multirow{2}{*}{$\begin{array}{l}\text { Lim } \\
\text { Model }\end{array}$} \\
\hline & ${ }^{\mathrm{a}} \mathrm{TP}$ and $\mathrm{M}$ & IP and $\mathrm{M}$ & $\mathrm{TP}$ and $\mathrm{V}$ & IP and $V$ & \\
\hline${ }^{b}$ All the sediment $(\mathrm{N}=23)$ & 0.567 & 0.529 & 0.554 & 0.528 & 1.062 \\
\hline Accusand $(\mathrm{N}=10)$ & 0.860 & 0.782 & 0.834 & 0.756 & 1.562 \\
\hline Natural soil $(\mathrm{N}=9)$ & 0.358 & 0.349 & 0.359 & 0.338 & 0.292 \\
\hline Bioretention media $(\mathrm{N}=4)$ & 0.306 & 0.301 & 0.291 & 0.386 & 1.544 \\
\hline \multirow{2}{*}{$E_{l}$} & \multicolumn{4}{|c|}{ K-C Model } & Lim \\
\hline & $\mathrm{TP}$ and $\mathrm{M}$ & IP and $\mathrm{M}$ & $\mathrm{TP}$ and $\mathrm{V}$ & IP and V & Model \\
\hline All the sediment $(\mathrm{N}=23)$ & 0.463 & 0.500 & 0.476 & 0.500 & -0.004 \\
\hline Accusand $(\mathrm{N}=10)$ & -0.774 & -0.613 & -0.721 & -0.560 & -2.222 \\
\hline Natural soil $(\mathrm{N}=9)$ & 0.187 & 0.208 & 0.185 & 0.231 & 0.338 \\
\hline Bioretention media $(\mathrm{N}=4)$ & -0.394 & -0.370 & -0.327 & -0.759 & -6.035 \\
\hline
\end{tabular}

${ }^{a} \mathrm{TP}, \mathrm{IP}, \mathrm{M}, \mathrm{V}$ represent total porosity, interporosity, $S_{m}$ by mass, and $S_{v}$ by volume, respectively, in the $\mathrm{K}-\mathrm{C}$ model.

${ }^{b} \mathrm{~N}=23, \mathrm{~N}=10, \mathrm{~N}=9$, and $\mathrm{N}=4$ represent the numbers of samples.

Table 3.5: $\quad M A E$ and $E_{1}$ for K-C and Lim model predictions of $\log (K)$ excluding large biochar particle samples (ACS (35)-6L, ACS (35)-6L*, ACS (40)$4 \mathrm{~L}$ and $\mathrm{BIM}-4 \mathrm{~L})$. The shaded numbers represent the best prediction for each row.

\begin{tabular}{|c|c|c|c|c|c|}
\hline \multirow{2}{*}{$M A E$} & \multicolumn{4}{|c|}{ K-C Model } & \multirow{2}{*}{$\begin{array}{l}\text { Lim } \\
\text { Model }\end{array}$} \\
\hline & ${ }^{\mathrm{a}} \mathrm{TP}$ and $\mathrm{M}$ & IP and $\mathrm{M}$ & $\mathrm{TP}$ and $\mathrm{V}$ & IP and $\mathrm{V}$ & \\
\hline All the sediment $(\mathrm{N}=19)$ & 0.399 & 0.404 & 0.385 & 0.406 & 0.907 \\
\hline Accusand $(\mathrm{N}=7)$ & 0.538 & 0.541 & 0.488 & 0.490 & 1.469 \\
\hline Natural soil $(\mathrm{N}=9)$ & 0.358 & 0.349 & 0.359 & 0.338 & 0.292 \\
\hline Bioretention media $(\mathrm{N}=3)$ & 0.197 & 0.252 & 0.223 & 0.412 & 1.445 \\
\hline \multirow{2}{*}{$E_{1}$} & \multicolumn{4}{|c|}{ K-C Model } & Lim \\
\hline & $\mathrm{TP}$ and $\mathrm{M}$ & IP and $\mathrm{M}$ & $\mathrm{TP}$ and $\mathrm{V}$ & IP and V & Model \\
\hline All the sediment $(\mathrm{N}=19)$ & 0.624 & 0.619 & 0.637 & 0.617 & 0.144 \\
\hline Accusand $(\mathrm{N}=7)$ & 0.059 & 0.055 & 0.148 & 0.143 & -1.567 \\
\hline Natural soil $(\mathrm{N}=9)$ & 0.187 & 0.208 & 0.185 & 0.231 & 0.338 \\
\hline Bioretention media $(\mathrm{N}=3)$ & 0.108 & -0.145 & -0.012 & -0.870 & -5.562 \\
\hline
\end{tabular}



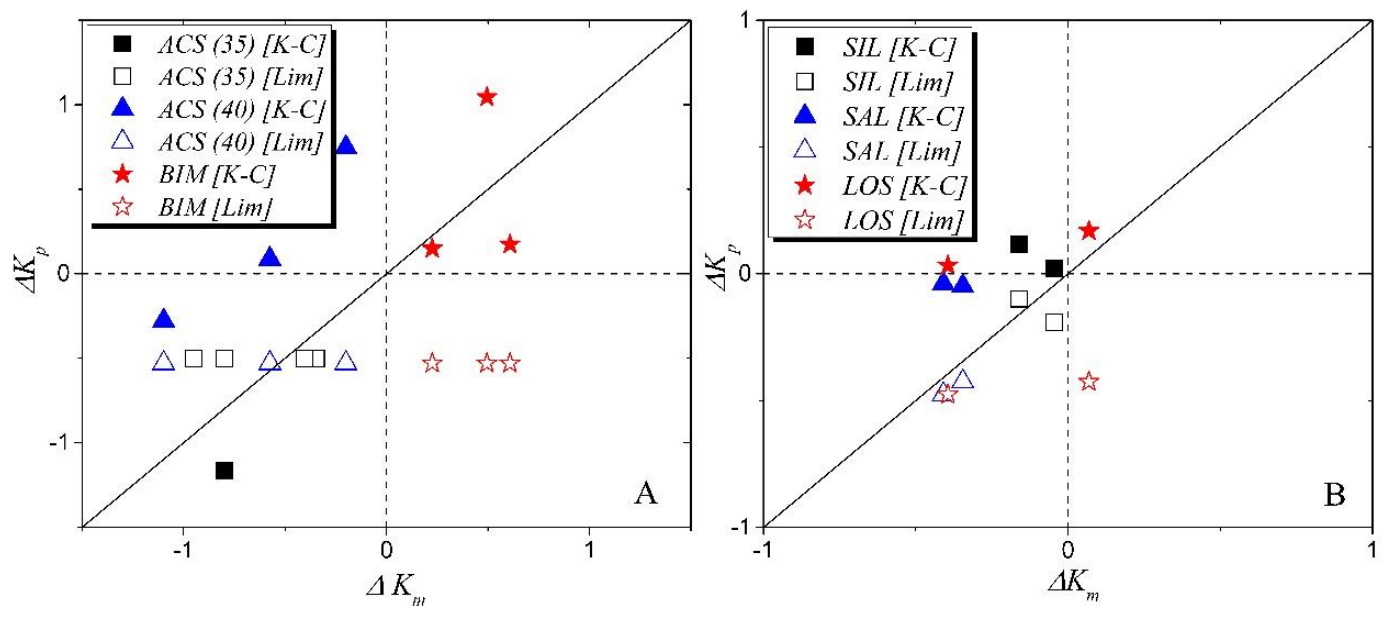

Figure 3.6: $\Delta K_{m}$ vs $\Delta K_{p}$ for Accusand and BIM (A) or for natural soils (B) using K-C and Lim models. Data in the top right and bottom left quadrants of each plot are where sign of $\Delta K_{m}$ and $\Delta K_{p}$ are identical.

Table 3.6: The $M A E$ and $E_{l}$ of $\Delta K_{m}$ and $\Delta K_{p}$ from equations (3-11) and (3-12), respectively, for K-C and Lim models. The shaded numbers represent the best prediction for each row.

\begin{tabular}{|c|c|c|c|c|c|}
\hline \multirow{2}{*}{$M A E$} & \multicolumn{4}{|c|}{ K-C Model } & \multirow{2}{*}{$\begin{array}{l}\text { Lim } \\
\text { Model }\end{array}$} \\
\hline & ${ }^{\mathrm{a}} \mathrm{TP}$ and $\mathrm{M}$ & IP and $\mathrm{M}$ & $\mathrm{TP}$ and $\mathrm{V}$ & IP and V & \\
\hline${ }^{\mathrm{b}}$ All the sediment $(\mathrm{N}=17)$ & 0.727 & 0.586 & 0.709 & 0.587 & 0.409 \\
\hline Accusand $(\mathrm{N}=8)$ & 1.056 & 0.959 & 1.022 & 0.925 & 0.388 \\
\hline Natural soil $(\mathrm{N}=6)$ & 0.419 & 0.206 & 0.466 & 0.253 & 0.156 \\
\hline Bioretention media $(\mathrm{N}=3)$ & 0.467 & 0.351 & 0.359 & 0.356 & 0.972 \\
\hline \multirow{2}{*}{$E_{l}$} & \multicolumn{4}{|c|}{ K-C Model } & Lim \\
\hline & $\mathrm{TP}$ and $\mathrm{M}$ & IP and $\mathrm{M}$ & $\mathrm{TP}$ and $\mathrm{V}$ & IP and V & Model \\
\hline All the sediment $(\mathrm{N}=17)$ & -0.654 & -0.296 & -0.565 & -0.296 & 0.097 \\
\hline Accusand $(\mathrm{N}=8)$ & -1.229 & -1.024 & -1.158 & -0.953 & 0.181 \\
\hline Natural soil (N=6) & -1.485 & -0.222 & -1.762 & -0.498 & 0.077 \\
\hline Bioretention media $(\mathrm{N}=3)$ & -2.220 & -1.422 & -1.476 & -1.454 & -5.712 \\
\hline
\end{tabular}

a TP, IP, M, V represent total porosity, interporosity, $S_{m}$ by mass, and $S_{v}$ by volume, respectively, in the $\mathrm{K}-\mathrm{C}$ model.

${ }^{b} \mathrm{~N}=23, \mathrm{~N}=10, \mathrm{~N}=9$, and $\mathrm{N}=4$ represent the numbers of samples 
Table 3.7: The $M A E$ and $E_{1}$ of $\Delta K_{m}$ and $\Delta K_{p}$ from equations (3-11) and (3-12), respectively, for $\mathrm{K}-\mathrm{C}$ and Lim models excluding large particle biochar samples (ACS (35)-6L, ACS (35)-6L*, ACS (40)-4L and BIM-4L). The shaded numbers represent the best prediction for each row.

\begin{tabular}{|c|c|c|c|c|c|}
\hline \multirow{2}{*}{$M A E$} & \multicolumn{4}{|c|}{ K-C Model } & \multirow{2}{*}{$\begin{array}{c}\text { Lim } \\
\text { Model }\end{array}$} \\
\hline & ${ }^{\mathrm{a}} \mathrm{TP}$ and $\mathrm{M}$ & IP and $\mathrm{M}$ & $\mathrm{TP}$ and $\mathrm{V}$ & IP and $\mathrm{V}$ & \\
\hline${ }^{\mathrm{b}}$ All the sediment $(\mathrm{N}=13)$ & 0.517 & 0.408 & 0.496 & 0.413 & 0.384 \\
\hline Accusand $(\mathrm{N}=5)$ & 1.030 & 0.910 & 0.981 & 0.862 & 0.405 \\
\hline Natural soil $(\mathrm{N}=6)$ & 0.419 & 0.206 & 0.466 & 0.253 & 0.156 \\
\hline Bioretention media $(\mathrm{N}=2)$ & 0.263 & 0.184 & 0.171 & 0.260 & 0.946 \\
\hline \multirow{2}{*}{$E_{1}$} & \multicolumn{4}{|c|}{ K-C Model } & Lim \\
\hline & $\mathrm{TP}$ and $\mathrm{M}$ & IP and $\mathrm{M}$ & $\mathrm{TP}$ and $\mathrm{V}$ & IP and $\mathrm{V}$ & Model \\
\hline All the sediment $(\mathrm{N}=13)$ & -0.087 & 0.143 & -0.043 & 0.132 & 0.192 \\
\hline Accusand $(\mathrm{N}=5)$ & -0.656 & -0.464 & -0.578 & -0.385 & 0.349 \\
\hline Natural soil $(\mathrm{N}=6)$ & -1.485 & -0.222 & -1.762 & -0.498 & 0.077 \\
\hline Bioretention media $(\mathrm{N}=2)$ & -0.376 & 0.039 & 0.108 & -0.358 & -3.947 \\
\hline
\end{tabular}

a $\mathrm{TP}, \mathrm{IP}, \mathrm{M}, \mathrm{V}$ represent total porosity, interporosity, $S_{m}$ by mass, and $S_{v}$ by volume, respectively, in the $\mathrm{K}-\mathrm{C}$ model.

${ }^{b} \mathrm{~N}=23, \mathrm{~N}=10, \mathrm{~N}=9$, and $\mathrm{N}=4$ represent the numbers of samples

\subsubsection{Relation between $K$ and Sediment Texture}

The interporosity has a positive relationship with $K$, as shown in Figure 3-3.

When $d_{50}$ of the sediment increases from 0.0185 to 0.752 , the slope of the regression lines shown in Figure 3-3 and listed in Table 3.8 also increase from $7.1 \pm 1.1$ to 1500 \pm 1000 . When sediment particles size is small, interporosity and $K$ are strongly correlated, as seen from large $R^{2}$ in the last column of the Table 3.8. But as $d_{50}$ increases, the correlation weakens and $R^{2}$ approaches zero: other parameters play a more significant role as sediment $d_{50}$ becomes large. 
Table 3.8: $\quad$ Relation between $d_{50}$ and $K$.

\begin{tabular}{lccc}
\hline \multicolumn{1}{c}{${ }^{\mathrm{a}}$ Sediment } & $d_{50}$ & ${ }^{\mathrm{b}}$ Slope $(\mathrm{cm} / \mathrm{h})$ & $\mathrm{R}^{2}$ \\
\hline SIL-0\%U, 2\%U, 6\%U & 0.0185 & $7.1 \pm 1.1$ & 0.98 \\
SAL-0\%U, 2\%U, 6\%U & 0.209 & $150 \pm 50$ & 0.91 \\
LOS-0\%U, 2\%U, 6\%U & 0.258 & $200 \pm 190$ & 0.48 \\
ACS (40)-0\%, 4\%S, 4\%U, 4\%L & 0.541 & $1800 \pm 400$ & 0.93 \\
ACS (35)-0\%, 6\%U, 6\%L, 6\%M, 6\%S & 0.545 & $1000 \pm 300$ & 0.74 \\
BIM-0\%, 4\%S, 4\%U, 4\%L & 0.752 & $1500 \pm 1000$ & 0.48 \\
\hline
\end{tabular}

${ }^{a}$ Abbreviations defined in Table 3.1.

$\mathrm{b}$ The slopes are of regressed lines in Figure 3-3 (interporosity versus measured $K$ ). 


\section{Chapter 4}

\section{CONCLUSIONS}

This study demonstrated that saturated hydraulic conductivity $(K)$ of biocharamended sediments are influenced by the particle size distribution of sediment, interporosity, sediment texture, and biochar texture. In the uniform sands, $K$ decreased after adding different biochars, and in the natural soils $K$ also decreased with biochar amendment. However, in bioretention media, $K$ increased with biochar amendment. These effects on $K$ are a function of interporosity and specific surface area, and were accounted for reasonably well with a revised Kozeny-Carmen model that replaced total sample porosity with interporosity, and the specific particle surface area from a mass-based particle size distribution with that from a volume-based particle size distribution. While the Kozeny-Carmen model predicted absolute $K$ best, if the objective is predicting the direction and magnitude of the change in $K$ with biochar amendment the Lim model was best. Both the Kozeny-Carmen and Lim models predicted $K$ poorly when large biochar particles amended the sediments.

In the future, more research should be conducted to better assess the impact of biochar of varying particle size and shape on $K$. The shape of biochar, segregation of sediment and biochar, and roughness of biochar surfaces likely also affect the specific surface area in the Kozeny-Carmen model. Finally, this study did not examine the role of soil aggregation on $K$, which is a time-dependent process and may involve microbial processes. 


\section{REFERENCES}

Asai, H., B. K. Samson, H. M. Stephan, K. Songyikhangsuthor, K. Homma, Y. Kiyono, Y. Inoue, T. Shiraiwa and T. Horie (2009). "Biochar amendment techniques for upland rice production in Northern Laos." Field Crops Research 111(1-2): 81-84.

ASTM (2007). Standard Test Method for Particle-Size Analysis of Soils: PP-5.

ASTM (2010). Standard test method for determination of pore volume and pore volume distribution of soil and rock by mercury intrusion porosimetry. West Conshohocken, PA.

ASTM (2013). Standard Terminology Relating to Catalysts and Catalysis: PP.

ASTM (2014). Standard Test Method for Sieve Analysis of Fine and Coarse Aggregates: PP-3.

Barnes, R. T., M. E. Gallagher, C. A. Masiello, Z. Liu and B. Dugan (2014). "Biocharinduced changes in soil hydraulic conductivity and dissolved nutrient fluxes constrained by laboratory experiments." PLoS One 9(9): e108340.

Carman (1937). "Trans. Inst. Chem. Engrs. (London)." 15,160.

Chan, K. Y., L. Van Zwieten, I. Meszaros, A. Downie and S. Joseph (2007).

"Agronomic values of greenwaste biochar as a soil amendment." Australian Journal of Soil Research 45(8): 629.

Chapuis, R. P. (2012). "Predicting the saturated hydraulic conductivity of soils: a review." Bulletin of Engineering Geology and the Environment 71(3): 401-434.

Chapuis, R. P. and M. Aubertin (2003). "On the use of the Kozeny-Carman equation to predict the hydraulic conductivity of soils." Canadian Geotechnical Journal 40(3): 616-628.

Devereux, R. C., C. J. Sturrock and S. J. Mooney (2013). "The effects of biochar on soil physical properties and winter wheat growth." Earth and Environmental Science Transactions of the Royal Society of Edinburgh 103(01): 13-18.

Dolzyk, K. and I. Chmielewska (2014). "Predicting the Coefficient of Permeability of Non-Plastic Soils." Soil Mechanics and Foundation Engineering 51(5): 213-218.

Eibisch, N., W. Durner, M. Bechtold, R. Fuß, R. Mikutta, S. K. Woche and M. Helfrich (2015). "Does water repellency of pyrochars and hydrochars counter their positive effects on soil hydraulic properties?" Geoderma 245-246: 31-39. 
Fair, G., Hatch, L, P., Hudso, H.E., and Jr. (1933). "FUNDAMENTAL FACTORS GOVERNING THE STREAMLINE FLOW OF WATER THROUGH SAND [with DISCUSSION]." Journal - American Water Works Association 25(11): 1551-1565.

Githinji, L. (2013). "Effect of biochar application rate on soil physical and hydraulic properties of a sandy loam." Archives of Agronomy and Soil Science 60(4): 457-470.

Jury, W. A. H., Robert (2004). Soil Physics. Hoboken, NJ, Wiley.

Legare, R. P. C. a. P.-P. (1992). "A simple method for determining the surface area of fine aggregates and fillers in bituminous mixtures." American Society for Testing and Materials, Philadelphia.

Legates, D. R. and G. J. McCabe (1999). "Evaluating the use of "goodness-of-fit" Measures in hydrologic and hydroclimatic model validation." Water Resources Research 35(1): 233-241.

Lei, O. and R. Zhang (2013). "Effects of biochars derived from different feedstocks and pyrolysis temperatures on soil physical and hydraulic properties." Journal of Soils and Sediments 13(9): 1561-1572.

Lim, T. J., K. A. Spokas, G. Feyereisen and J. M. Novak (2016). "Predicting the impact of biochar additions on soil hydraulic properties." Chemosphere 142: 136-144.

Liu, Z., B. Dugan, C. A. Masiello, R. T. Barnes, M. E. Gallagher and H. Gonnermann (2016). "Impacts of biochar concentration and particle size on hydraulic conductivity and DOC leaching of biochar-sand mixtures." Journal of Hydrology 533: 461-472.

M. H. Schroth, S. J. A., J. S. Selker, and J. D. Istok (1996). "Characterization of Miller-Similar Silica Sands for Laboratory Hydrologic Studies." Soil Sci. Soc. Am. J. : 1331-1339.

Mukherjee, A. and R. Lal (2013). "Biochar Impacts on Soil Physical Properties and Greenhouse Gas Emissions." Agronomy 3(2): 313-339.

Shahabi, A. A., Das, B.M., Tarquin, A.J. (1984). "Empirical relation for coefficient of permeability of sand." Nat Conf Pub, Inst of Engineers, Australia: 84(82): 5457.

Steiakakis, E., C. Gamvroudis and G. Alevizos (2012). "Kozeny-Carman Equation and Hydraulic Conductivity of Compacted Clayey Soils." Geomaterials 02(02): 37-41.

W. David Carrier III, F. A. (2003). "Goodbye, Hazenl Hello, Kozeny-Carman." Geotechnical and Geoenvironmental Engineering: 1054-1056. 
Wyllie, M. R. J., Gregory, A. R. (1955). "Fluid Flow through Unconsolidated Porous Aggregates-Effect of Porosity and Particle Shape on Kozeny-Carman Constants." INDUSTRIAL AND ENGINEERING CHEMISTRY: 1379. 


\section{Appendix}

\section{NORMALIZATION OF MAE AND $E_{1}$}

Tables A.1 and A.2 list $M A E$ and $E_{l}$ of $\log (K)$ and $\Delta K$ normalized by standard deviation (SD) and/or mean. The top four rows in Tables A.1 and A.2 are identical to rows in Tables 3.4 and 3.6, respectively. To compare two models, in this case the K-C and Lim models, Legates and McCabe (1999) suggest eliminating the difference between the mean of measured and model prediction, and/or correcting for differences in the standard deviation of measured and model predictions $(\log (K)$ or $\Delta K)$ before computing $M A E$ and $E_{l}$. Three different normalizations of the data were performed:

(1) Normalize only with respect to the difference between mean measured and mean model prediction (The second four rows in Tables A.1 and A.2):

$$
P_{i}^{m}=P_{i}-\left(M\left(P_{i}\right)-M\left(O_{i}\right)\right)
$$

where $O_{i}$ is either $\log \left(K_{m}\right)$ or $\log \left(K_{m_{c}}\right)$, and $P_{i}$ is either $\log \left(K_{p}\right)$ or $\log \left(K_{p_{c}}\right)$ predicted by K-C or Lim models. Alternatively, $O_{i}$ is $\Delta K_{m} ; P_{i}$ is $\Delta K_{p}$ predicted by K-C or Lim models. $M\left(P_{i}\right)$ is the mean of $P_{i}$ and $M\left(O_{i}\right)$ is the mean of $O_{i} . P_{i}^{m}$ is the new prediction data normalized by means.

(2) Normalize only respect to the standard deviation of measured and model predictions (The third four rows in Table A.1 and Table A.2):

$$
P_{i}^{S D}=P_{i} \times \frac{S D\left(O_{i}\right)}{S D\left(P_{i}\right)}
$$

$P_{i}^{S D}$ is the new prediction data normalized by standard deviation $(S D) . S D\left(O_{i}\right)$ and $S D$ $\left(P_{i}\right)$ are standard deviation of $O_{i}$ and $P_{i}$, respectively.

(3) Normalize with both the mean and standard deviation (The fourth four rows in Table A.1 and Table A.2): 


$$
P_{i}^{S D, m}=P_{i} \times \frac{S D\left(O_{i}\right)}{S D\left(P_{i}\right)}-\left(M\left(P_{i}^{S D}\right)-M\left(O_{i}\right)\right)
$$

$P_{i}^{S D, m}$ is the new prediction data normalized by mean and standard deviation.

The last four rows of Tables A.1 and A.2 present the results with this method. When the data are normalized by the mean and standard deviation, the $\mathrm{K}-\mathrm{C}$ model is better than the Lim model. 
Table A.1: The $M A E$ and $E_{l}$ of $\log (K)$ for different sediments and different models (K-C model and Lim's model). The shaded numbers represent the best prediction for each row.

\begin{tabular}{|c|c|c|c|c|c|c|c|c|c|c|}
\hline & \multicolumn{5}{|c|}{ MAE ( ${ }^{a}$ Initial) } & \multicolumn{5}{|c|}{$\mathrm{E}_{1}$ (Initial) } \\
\hline & \multicolumn{4}{|c|}{ K-C Model } & \multirow{2}{*}{$\begin{array}{c}\text { Lim } \\
\text { Model }\end{array}$} & \multicolumn{4}{|c|}{ K-C Model } & \multirow{2}{*}{$\begin{array}{c}\text { Lim } \\
\text { Model }\end{array}$} \\
\hline & ${ }^{\mathrm{c}} \mathrm{TP}$ and $\mathrm{M}$ & IP and $\mathrm{M}$ & $\mathrm{TP}$ and $\mathrm{V}$ & IP and V & & $\mathrm{TP}$ and $\mathrm{M}$ & IP and $\mathrm{M}$ & $\mathrm{TP}$ and $\mathrm{V}$ & IP and V & \\
\hline${ }^{\mathrm{d}}$ All the sediment $(\mathrm{N}=23)$ & 0.567 & 0.529 & 0.554 & 0.528 & 1.062 & 0.463 & 0.500 & 0.476 & 0.500 & -0.004 \\
\hline Accusand $(\mathrm{N}=10)$ & 0.860 & 0.782 & 0.834 & 0.756 & 1.562 & -0.774 & -0.613 & -0.721 & -0.560 & -2.222 \\
\hline Natural soil $(\mathrm{N}=9)$ & 0.358 & 0.349 & 0.359 & 0.338 & 0.292 & 0.187 & 0.208 & 0.185 & 0.231 & 0.338 \\
\hline \multirow[t]{4}{*}{ Bioretention media $(\mathrm{N}=4)$} & 0.306 & 0.301 & 0.291 & 0.386 & 1.544 & -0.394 & -0.370 & -0.327 & -0.759 & -6.035 \\
\hline & \multicolumn{5}{|c|}{ MAE ('Mean_Normalized) } & \multicolumn{5}{|c|}{ E 1 (Mean_Normalized) } \\
\hline & \multicolumn{4}{|c|}{ K-C Model } & Lim & \multicolumn{4}{|c|}{ K-C Model } & Lim \\
\hline & $\mathrm{TP}$ and $\mathrm{M}$ & IP and $\mathrm{M}$ & $\mathrm{TP}$ and $\mathrm{V}$ & IP and V & Model & $\mathrm{TP}$ and $\mathrm{M}$ & IP and $\mathrm{M}$ & $\mathrm{TP}$ and $\mathrm{V}$ & IP and V & Model \\
\hline All the sediment $(\mathrm{N}=23)$ & 0.593 & 0.551 & 0.582 & 0.540 & 0.844 & 0.439 & 0.479 & 0.449 & 0.490 & 0.201 \\
\hline Accusand $(\mathrm{N}=10)$ & 0.690 & 0.662 & 0.664 & 0.636 & 0.316 & -0.423 & -0.365 & -0.370 & -0.312 & 0.349 \\
\hline Natural soil $(\mathrm{N}=9)$ & 0.365 & 0.329 & 0.369 & 0.333 & 0.236 & 0.170 & 0.252 & 0.161 & 0.242 & 0.464 \\
\hline Bioretention media $(\mathrm{N}=4)$ & 0.306 & 0.263 & 0.270 & 0.270 & 0.365 & -0.394 & -0.199 & -0.229 & -0.231 & -0.662 \\
\hline
\end{tabular}

${ }^{a}$ using initial $O_{i}$ and $P_{i}$ : results are identical to Table 3.4. No normalization of the data.

${ }^{\mathrm{b}}$ using $P_{i}^{m}$ value

${ }^{\mathrm{c}} \mathrm{TP}$, IP, M, V represent total porosity, interporosity, $S_{m}$ by mass, and $S_{v}$ by volume, respectively, in the K-C model.

${ }^{\mathrm{d}} \mathrm{N}=23, \mathrm{~N}=10, \mathrm{~N}=9$, and $\mathrm{N}=4$ represent the numbers of samples. 
Table A.1 continued.

\begin{tabular}{|c|c|c|c|c|c|c|c|c|c|c|}
\hline & \multicolumn{5}{|c|}{ MAE ( $\left.{ }^{a} S D \_N o r m a l i z e d\right)$} & \multicolumn{5}{|c|}{$\mathrm{E}_{1}$ (SD_Normalized) } \\
\hline & \multicolumn{4}{|c|}{ K-C Model } & \multirow{2}{*}{$\begin{array}{l}\text { Lim } \\
\text { Model }\end{array}$} & \multicolumn{4}{|c|}{ K-C Model } & \multirow{2}{*}{$\begin{array}{l}\text { Lim } \\
\text { Model }\end{array}$} \\
\hline & $\mathrm{TP}$ and $\mathrm{M}$ & IP and $\mathrm{M}$ & $\mathrm{TP}$ and $\mathrm{V}$ & IP and $\mathrm{V}$ & & $\mathrm{TP}$ and $\mathrm{M}$ & IP and $\mathrm{M}$ & $\mathrm{TP}$ and $\mathrm{V}$ & IP and $\mathrm{V}$ & \\
\hline All the sediment $(\mathrm{N}=23)$ & 0.431 & 0.421 & 0.450 & 0.438 & 0.699 & 0.592 & 0.602 & 0.574 & 0.585 & 0.339 \\
\hline Accusand $(\mathrm{N}=10)$ & 0.488 & 0.633 & 0.467 & 0.631 & 0.937 & -0.007 & -0.305 & 0.038 & -0.301 & -0.933 \\
\hline Natural soil $(\mathrm{N}=9)$ & 0.352 & 0.354 & 0.360 & 0.352 & 0.365 & 0.199 & 0.196 & 0.181 & 0.199 & 0.170 \\
\hline \multirow[t]{4}{*}{ Bioretention media $(\mathrm{N}=4)$} & 1.080 & 1.036 & 1.059 & 1.075 & 1.521 & -3.920 & -3.720 & -3.826 & -3.899 & -5.932 \\
\hline & \multicolumn{5}{|c|}{ MAE ('SD and Mean_Normalized) } & \multicolumn{5}{|c|}{$\mathrm{E}_{1}$ (SD and Mean_Normalized) } \\
\hline & \multicolumn{4}{|c|}{ K-C Model } & Lim & \multicolumn{4}{|c|}{ K-C Model } & Lim \\
\hline & $\mathrm{TP}$ and $\mathrm{M}$ & IP and $\mathrm{M}$ & $\mathrm{TP}$ and $\mathrm{V}$ & IP and $\mathrm{V}$ & Model & $\mathrm{TP}$ and $\mathrm{M}$ & IP and $\mathrm{M}$ & $\mathrm{TP}$ and $\mathrm{V}$ & IP and $\mathrm{V}$ & Model \\
\hline All the sediment $(\mathrm{N}=23)$ & 0.431 & 0.424 & 0.449 & 0.441 & 0.699 & 0.593 & 0.599 & 0.575 & 0.582 & 0.339 \\
\hline Accusand $(\mathrm{N}=10)$ & 0.405 & 0.353 & 0.390 & 0.339 & 0.275 & 0.164 & 0.273 & 0.196 & 0.302 & 0.433 \\
\hline Natural soil $(\mathrm{N}=9)$ & 0.359 & 0.333 & 0.371 & 0.348 & 0.225 & 0.164 & 0.273 & 0.196 & 0.302 & 0.433 \\
\hline Bioretention media $(\mathrm{N}=4)$ & 0.135 & 0.163 & 0.156 & 0.190 & 0.371 & 0.382 & 0.258 & 0.290 & 0.136 & -0.692 \\
\hline
\end{tabular}

${ }^{\mathrm{a}}$ using $P_{i}^{S D}$

${ }^{\mathrm{b}} \mathrm{using} P_{i}^{S D, m}$ 
Table A.2: The $M A E$ and $E_{1}$ of delta $K\left(\Delta K_{m}\right.$ and $\Delta K_{p}$ in Equation (3-10) and (3-11), respectively) for different sediments and different models (K-C model and Lim model). The shaded numbers represent the best prediction for each row.

\begin{tabular}{|c|c|c|c|c|c|c|c|c|c|c|}
\hline & \multicolumn{5}{|c|}{ MAE (Initial) } & \multicolumn{5}{|c|}{$\mathrm{E}_{1}$ (Initial) } \\
\hline & \multicolumn{4}{|c|}{ K-C Model } & \multirow{2}{*}{$\begin{array}{l}\text { Lim } \\
\text { Model }\end{array}$} & \multicolumn{4}{|c|}{$\mathrm{K}-\mathrm{C}$ model } & \multirow{2}{*}{$\begin{array}{l}\text { Lim } \\
\text { Model }\end{array}$} \\
\hline & $\mathrm{TP}$ and $\mathrm{M}$ & IP and $\mathrm{M}$ & $\mathrm{TP}$ and $\mathrm{V}$ & IP and $V$ & & $\mathrm{TP}$ and $\mathrm{M}$ & IP and $\mathrm{M}$ & $\mathrm{TP}$ and $\mathrm{V}$ & IP and $\mathrm{V}$ & \\
\hline All the sediment & 0.749 & 0.587 & 0.728 & 0.589 & 0.409 & -0.654 & -0.296 & -0.606 & -0.299 & 0.097 \\
\hline Accusand & 1.069 & 0.959 & 1.038 & 0.926 & 0.388 & -1.258 & -1.025 & -1.191 & -0.956 & 0.181 \\
\hline Natural soil & 0.447 & 0.208 & 0.495 & 0.256 & 0.156 & -1.652 & -0.235 & -1.935 & -0.517 & 0.077 \\
\hline \multirow[t]{4}{*}{ Bioretention media } & 0.499 & 0.351 & 0.367 & 0.354 & 0.972 & -2.444 & -1.426 & -1.531 & -1.440 & -5.712 \\
\hline & \multicolumn{5}{|c|}{ MAE (Mean_Normalized) } & \multicolumn{5}{|c|}{ E 1 (Mean_Normalized) } \\
\hline & \multicolumn{4}{|c|}{ K-C Model } & Lim & \multicolumn{4}{|c|}{ K-C Model } & Lim \\
\hline & $\begin{array}{c}\mathrm{TP} \text { and } \mathrm{M} \\
0.491\end{array}$ & $\begin{array}{c}\text { IP and M } \\
0.496\end{array}$ & $\begin{array}{c}\mathrm{TP} \text { and } \mathrm{V} \\
0.475\end{array}$ & $\begin{array}{c}\text { IP and V } \\
0.482\end{array}$ & $\begin{array}{c}\text { Model } \\
0.389\end{array}$ & $\begin{array}{c}\text { TP and } \mathrm{M} \\
-0.084\end{array}$ & $\begin{array}{c}\text { IP and } \mathrm{M} \\
-0.094\end{array}$ & $\begin{array}{c}\mathrm{TP} \text { and } \mathrm{V} \\
-0.048\end{array}$ & $\begin{array}{c}\text { IP and V } \\
-0.065\end{array}$ & $\begin{array}{c}\text { Model } \\
0.141\end{array}$ \\
\hline Accusand & 0.568 & 0.626 & 0.551 & 0.595 & 0.377 & -0.199 & -0.322 & -0.163 & -0.257 & 0.205 \\
\hline Natural soil & 0.123 & 0.148 & 0.116 & 0.115 & 0.124 & 0.271 & 0.122 & 0.311 & 0.318 & 0.264 \\
\hline Bioretention media & 0.271 & 0.313 & 0.316 & 0.359 & 0.145 & -0.869 & -1.162 & -1.182 & -1.475 & 0.000 \\
\hline
\end{tabular}

a using initial $O_{i}$ and $P_{i}$ : results are identical to Table 3.6. No normalization of the data.

${ }^{\mathrm{b}}$ using $P_{i}^{m}$ value

${ }^{c} \mathrm{TP}, \mathrm{IP}, \mathrm{M}, \mathrm{V}$ represent total porosity, interporosity, $S_{m}$ by mass, and $S_{v}$ by volume, respectively, in the K-C model.

${ }^{\mathrm{d}} \mathrm{N}=23, \mathrm{~N}=10, \mathrm{~N}=9$, and $\mathrm{N}=4$ represent the numbers of samples. 
Table A. 2 continued.

\begin{tabular}{|c|c|c|c|c|c|c|c|c|c|c|}
\hline & \multicolumn{5}{|c|}{ MAE (SD_Normalized) } & \multicolumn{5}{|c|}{ E (SD_Normalized) } \\
\hline & \multicolumn{4}{|c|}{ K-C Model } & \multirow{2}{*}{$\begin{array}{l}\text { Lim } \\
\text { Model }\end{array}$} & \multicolumn{4}{|c|}{ K-C Model } & \multirow{2}{*}{$\begin{array}{l}\text { Lim } \\
\text { Model }\end{array}$} \\
\hline & $\mathrm{TP}$ and $\mathrm{M}$ & IP and $\mathrm{M}$ & $\mathrm{TP}$ and $\mathrm{V}$ & IP and $V$ & & $\mathrm{TP}$ and $\mathrm{M}$ & IP and $\mathrm{M}$ & $\mathrm{TP}$ and $\mathrm{V}$ & IP and V & \\
\hline All the sediment & 0.626 & 0.466 & 0.635 & 0.476 & 1.153 & -0.382 & -0.029 & -0.401 & -0.052 & -1.544 \\
\hline Accusand & 0.915 & 0.753 & 0.913 & 0.750 & 0.827 & -0.931 & -0.589 & -0.928 & -0.584 & -0.747 \\
\hline Natural soil & 0.526 & 0.209 & 0.531 & 0.304 & 0.229 & -2.119 & -0.238 & -2.146 & -0.804 & -0.357 \\
\hline \multirow[t]{4}{*}{ Bioretention media } & 0.183 & 0.169 & 0.163 & 0.269 & $5.4 \mathrm{E}+14$ & -0.263 & -0.166 & -0.125 & -0.857 & $-3.7 \mathrm{E}+15$ \\
\hline & \multicolumn{5}{|c|}{ MAE (SD and Mean_Normalized) } & \multicolumn{5}{|c|}{$\mathrm{E}_{1}$ (SD and Mean_Normalized) } \\
\hline & \multicolumn{4}{|c|}{ K-C Model } & Lim & \multicolumn{4}{|c|}{ K-C Model } & Lim \\
\hline & $\mathrm{TP}$ and $\mathrm{M}$ & IP and $\mathrm{M}$ & $\mathrm{TP}$ and $\mathrm{V}$ & IP and V & Model & $\mathrm{TP}$ and $\mathrm{M}$ & IP and $\mathrm{M}$ & $\mathrm{TP}$ and $\mathrm{V}$ & IP and $V$ & Model \\
\hline All the sediment & 0.388 & 0.371 & 0.392 & 0.376 & 0.424 & 0.143 & 0.182 & 0.134 & 0.170 & 0.064 \\
\hline Accusand & 0.288 & 0.269 & 0.266 & 0.249 & 0.268 & 0.392 & 0.431 & 0.438 & 0.475 & 0.434 \\
\hline Natural soil & 0.120 & 0.139 & 0.114 & 0.099 & 0.126 & 0.289 & 0.178 & 0.322 & 0.410 & 0.254 \\
\hline Bioretention media & 0.181 & 0.184 & 0.180 & 0.183 & 0.222 & -0.246 & -0.268 & -0.241 & -0.261 & -0.533 \\
\hline
\end{tabular}


Table A.3: The Max. Reynolds for all the sediments.

\begin{tabular}{cc}
\hline Sediment & Max. Reynolds \# \\
\hline ACS (35) & $1.98 \mathrm{E}-01$ \\
ACS (35)-6U & $2.44 \mathrm{E}-01$ \\
ACS (35)-6L & $2.94 \mathrm{E}-01$ \\
ACS (35)-6 L' & $2.42 \mathrm{E}-01$ \\
ACS (35)-6M & $1.98 \mathrm{E}-01$ \\
ACS (35)-6S & $1.31 \mathrm{E}-02$ \\
ACS (40) & $8.47 \mathrm{E}-01$ \\
ACS (40)-4S' & $2.98 \mathrm{E}-01$ \\
ACS (40)-4U' & $3.74 \mathrm{E}-01$ \\
ACS (40)-4L' & $4.68 \mathrm{E}-01$ \\
SIL & $4.03 \mathrm{E}-05$ \\
SIL-2U & $5.86 \mathrm{E}-05$ \\
SIL-6U & $1.03 \mathrm{E}-04$ \\
SAL & $3.49 \mathrm{E}-03$ \\
SAL-2U & $1.54 \mathrm{E}-03$ \\
SAL-6U & $2.00 \mathrm{E}-03$ \\
LOS & $1.25 \mathrm{E}-02$ \\
LOS-2U & $4.25 \mathrm{E}-03$ \\
LOS-6U & $1.37 \mathrm{E}-02$ \\
BIM & $8.49 \mathrm{E}-01$ \\
BIM-4S' & $3.61 \mathrm{E}-01$ \\
BIM-4U' & $8.45 \mathrm{E}-01$ \\
BIM-4L' & $4.22 \mathrm{E}-01$ \\
\hline
\end{tabular}




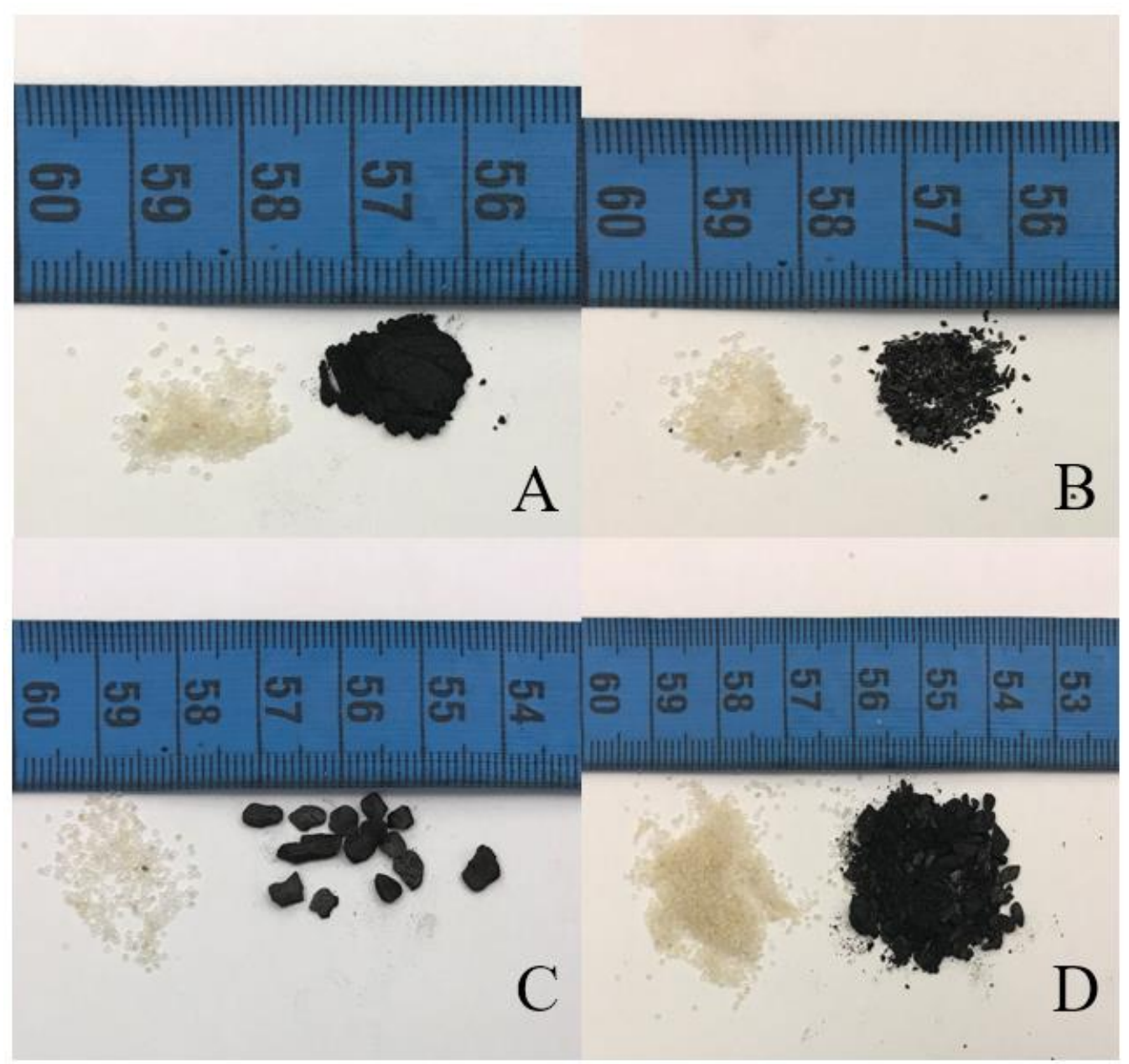

Figure A.1: A contains ACS (30/35) and Small biochar (0.001-0.059 mm). B contains ACS (30/35) and medium biochar $(0.5-0.59 \mathrm{~mm})$. C contains ACS (30/35) and large biochar (2-4.75 mm). D contains ACS (30/35) and unsieved biochar $(<4.75 \mathrm{~mm})$. 


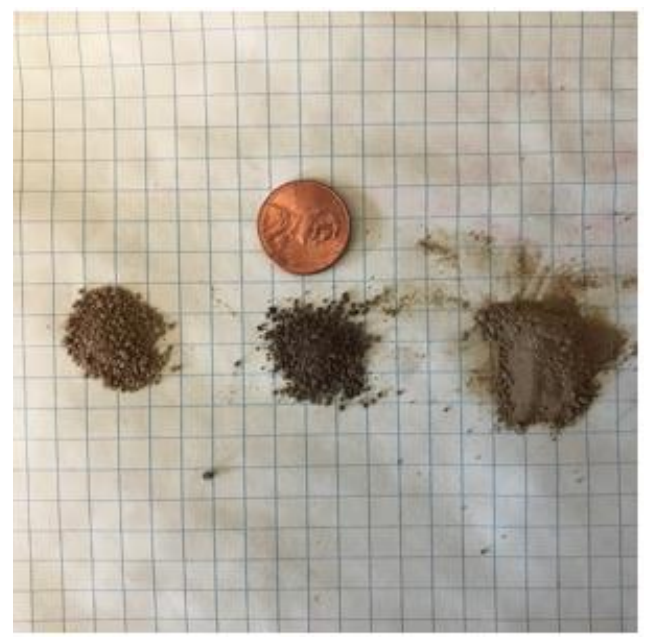

Figure A.2: The image of soil from right to left is silt loam, sandy loam and loam sand.

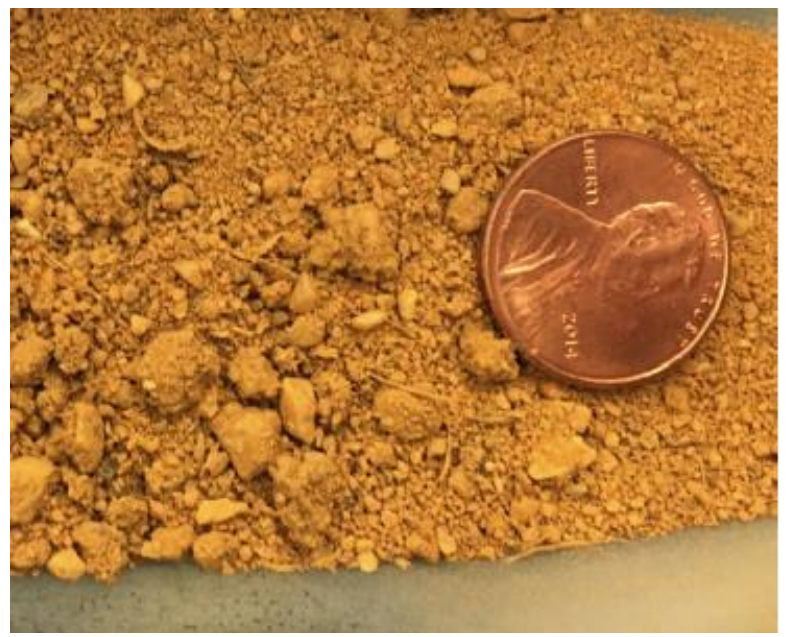

Figure A.3: Bioretention media. 


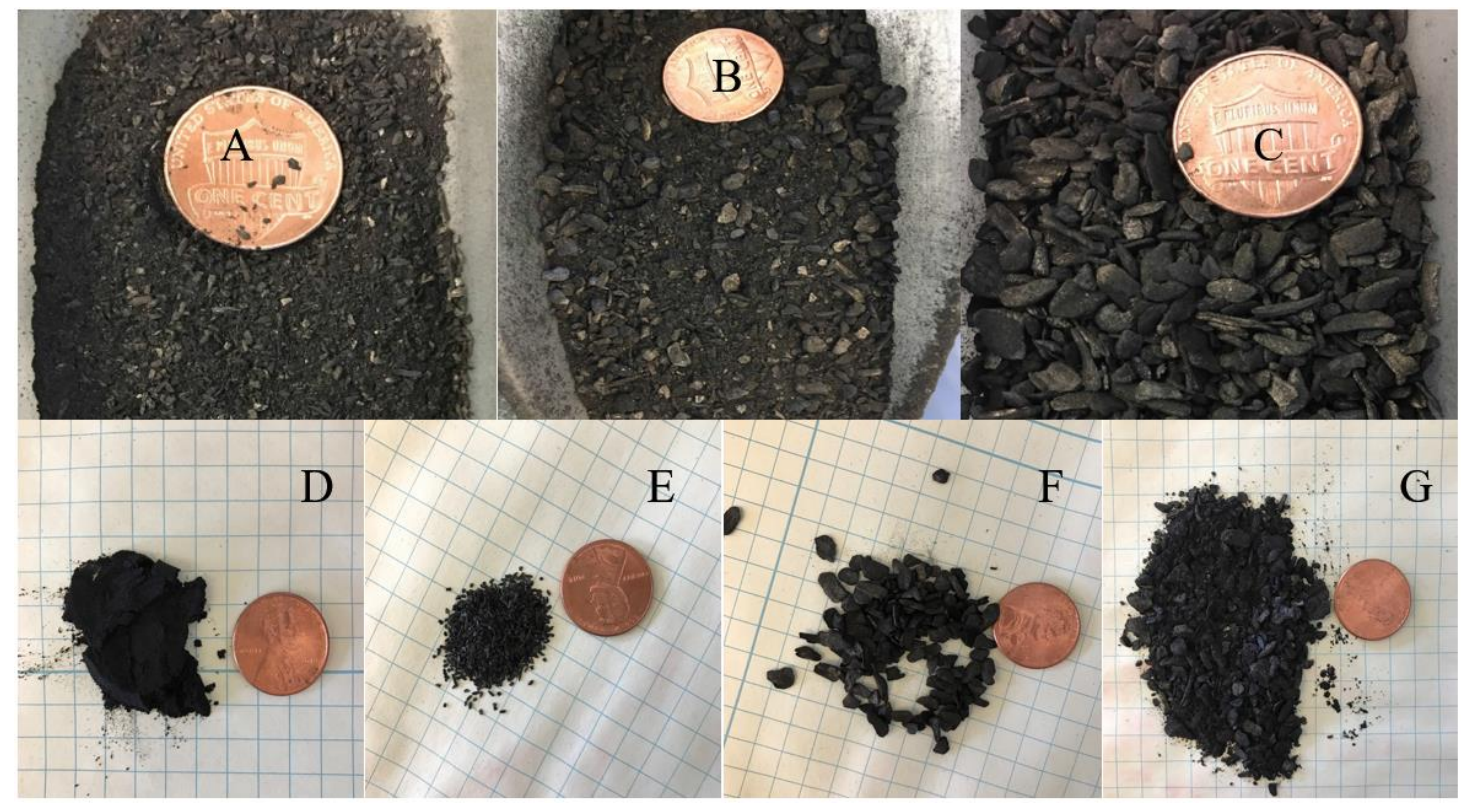

Figure A.4: A: small biochars $(<0.841 \mathrm{~mm})$, B: unsieved biochars $(<2 \mathrm{~mm}), \mathrm{C}$ : large biochars (0.841-4.75 mm), D: small biochars (0.001-0.059 mm), E: medium biochars $(0.5-0.59 \mathrm{~mm}), \mathrm{F}$ : large biochars $(2-4.75 \mathrm{~mm}), \mathrm{G}$ : and unsieved biochars $(<4.75 \mathrm{~mm})$. 

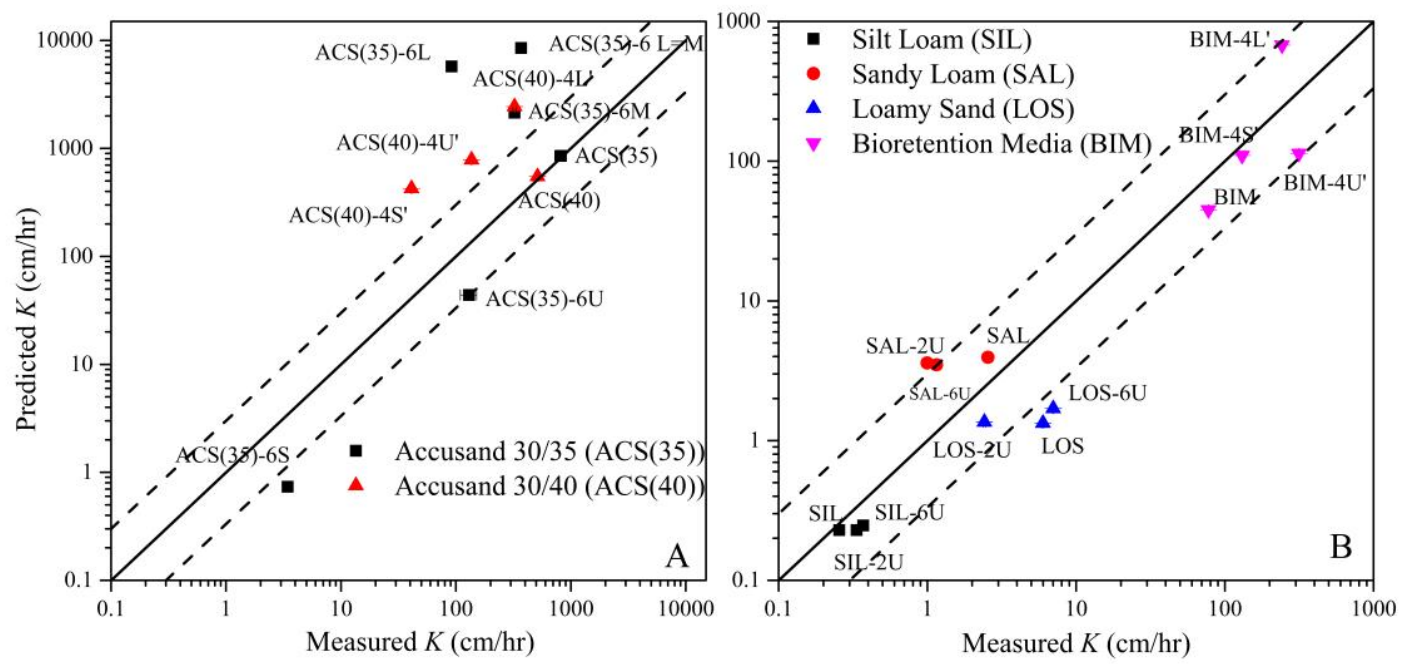

Figure A.5: A. and B. Predicted versus measured $K$ values computed by K-C model with $S_{m}$ and interporosity for the uniform sands, natural soils and bioretention media. The error bars in the plots are too small to be visible. 